\title{
ENVIRONMENTAL ADAPTATION OF URBAN PATTERN'S FOR CONTEMPORARY DISTRICTS IN RIYADH CITY
}

\section{Osama Saad Khalil}

(Recieved September 5, 2007 Accepted November 3, 2007)

\section{Research Problem:}

Riyadh City is affected by ecological systems, such as over heated periods, hinter desert, floodways and sand storms, This natural environmental factors formulating the characteristics of Riyadh City and reflect the principles of development that adapt with these factors. Therefore, the research discusses, "The adaptation of Riyadh pattern with ecological systems"

\section{Research Significance:}

Referring to Saudi Arabia concern of the importance of natural environmental and Contemporary Districts Planning in Riyadh City, The research aims at achieving urban environmental adaptation of existing built form of Riyadh City, Therefore it needs to establish ecological systems to support the goals of Riyadh structural plan, vision $1442 \mathrm{H}$

\section{Research Objectives:}

The research aims at focusing and making-use the adaptation of planning districts with ecological systems, this will help to place guidelines to contribute adaptation, which relates the requirements of human comfort and sustainable City.

\section{Research Methodology:}

The research will achieve objectives through four main parts, First part: Literature review including "theoretical studies" of environmental planning and urban form and Riyadh Strategic plan at -1442A.H. Second part: "Analytical studies" of Riyadh Region are carrying out within (parametric study \& parametric evaluation), Third part: Applications, selective patterns of Contemporary Districts Planning in Riyadh City, Fourth part: "Conclusion" design guide- lines.

\section{Conclusions \& recommendations:}

The research will conclude design and planning guidelines, which adapt with ecological systems in Riyadh. Therefore, it will achieve Environmental Adaptation of urban Pattern's for contemporary districts in Riyadh and the goals of Saudi Arabian's Strategy. 


\section{الأنماط العمرانية المتوافقة بيئياً مع الأحياء

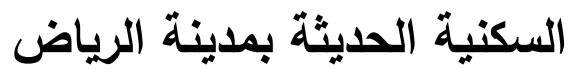

إعداد: د / أسامه سعد خليل إبراهيم

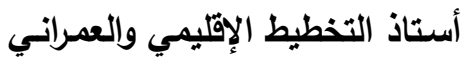

كلية العمارة والتخطيط - جامعة الملك سعود

\section{ملخص البحث--}

- تتسم مدينـة الرياض بخصائص مكانيـة وطبيعية خاصـة، نظراً للإجهاد الحراري الواقع على كتلنها

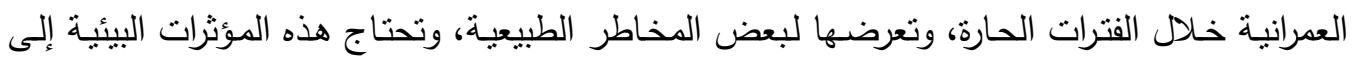

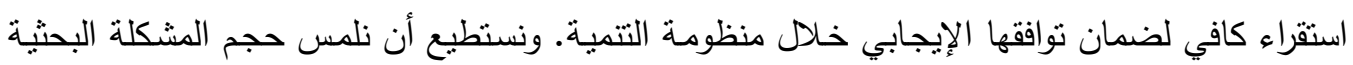

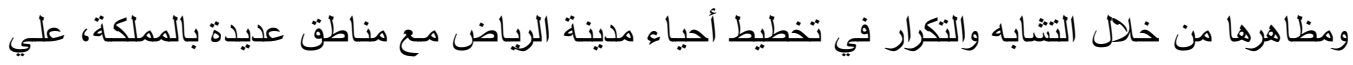
الرغم من التباين في خصائصها الطبيعية ومحدداتها المكانية وأهدافها العمرانية.

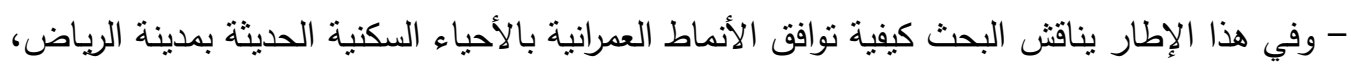

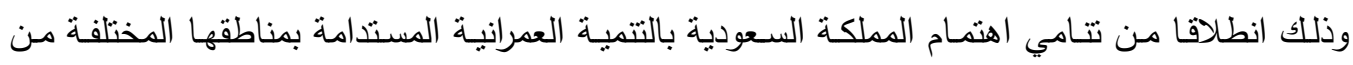

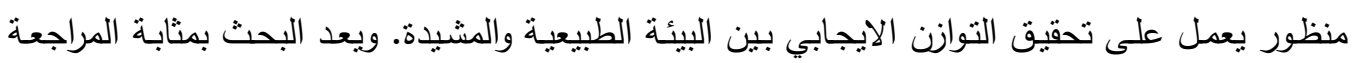

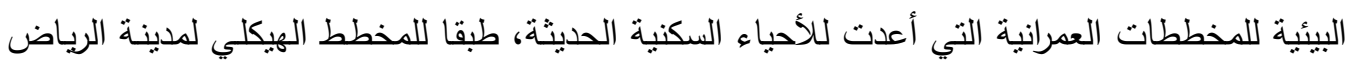
حتى عام (1442هـ). وتتضمن مراحل وأنشطة البحث "دراسات نظرية" تتاقش المداخل الفكرية البيئية

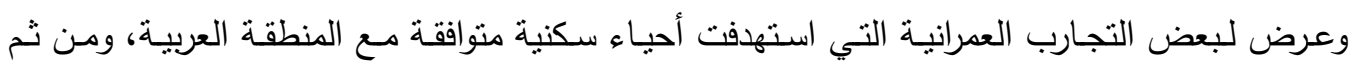
استخلاص الأسس والمعايير التي بستخدمها البحث في التقييم البيئي للحالات الدراسية.

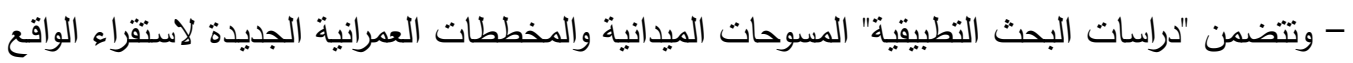
البيئي لأحباء مختارة في مدينـة الرياض، هي (الورود، الملك فيصل، الإسكان) وتعبر عن الأنماط

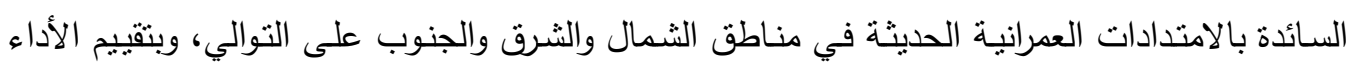

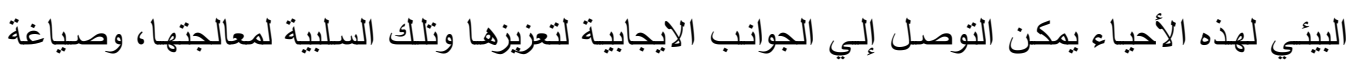
المعايير الإرشادية والضوابط العمرانية البيئية التي تساهم عملياً في تحقيق أهداف الاستراتيجية العمرانية الوطنية للمملكة العربية السعودية. 


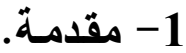

- تؤكد تقارير التتمية المستدامة الصادرة عن (الأمم المتحدة، سنة 2005م)، على أن معرفة خصائص النطاق المكاني والتأثثر المحيطي للبيئة الششيدة علم موجود وذو دراسات نظرية وتطبيقية واسعة، ورغم انه اثبت جدواه عالمياً في تحقيق الراحة لسكان المجتمعات الصحراوية بالمناطق الحارة وتوفير الطاقة الصنة

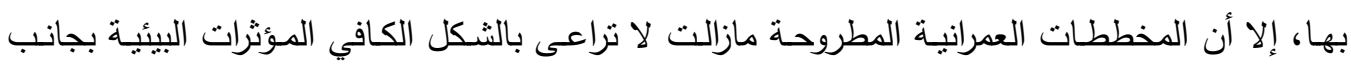
العمرانية والاقتصادية والاجتماعية.

\section{1-1 مشكلة البحث وأهميته:}

- تتمثل أهم مظاهر المشكلة البحثية في ارتفاع مؤشر استهلاك الطاقة المستنفة في تكييف المباني

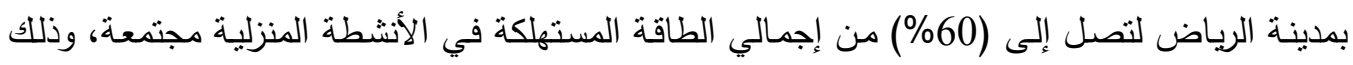

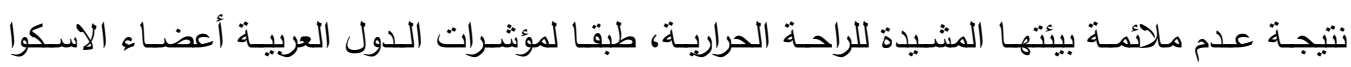

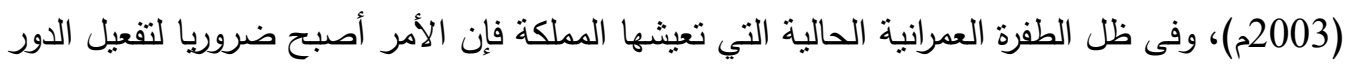
البيئي في تخطيط الحى باعنباره وحدة التشكيل الأولى بالمدينة.

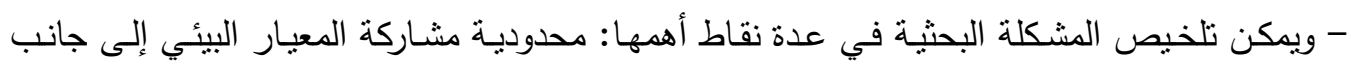

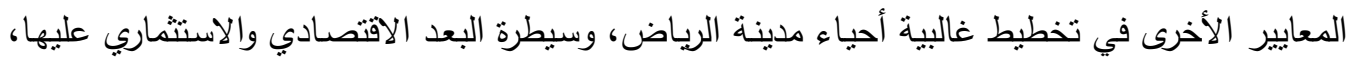

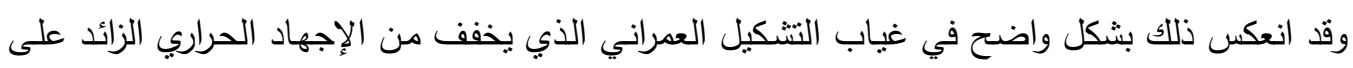

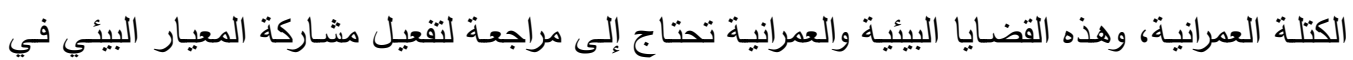
تخطيط الامتدادات العمرانية الجديدة بمدينة الرياض.

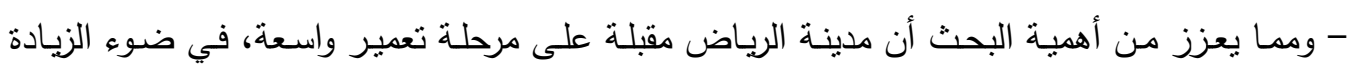
الملموسة في معدل نمو سكانها حوالى (8\% سنويا)، وتصل مساحة المناطق المطورة في المدينة حاليا

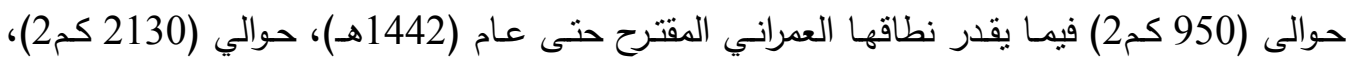

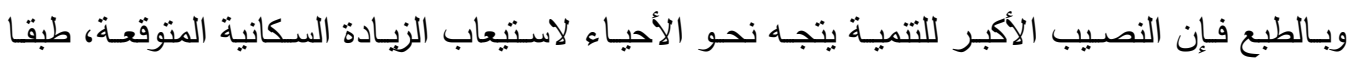
لمؤشرات (الهيئة العليا لنطوير الرياض، عام 1424هـ).

\section{1-2-1 أهداف البحث:}

- يهدف البحث إلى تفعيل الدور البيئي في اختيار الأنماط العمرانية بالأحياء السكنية الحديثة بمدينة الرياض، وذلك في إطار خصائص النطاق المكاني لها، وصياغة المعايير البيئية والخطوط الإرشادية الإئية

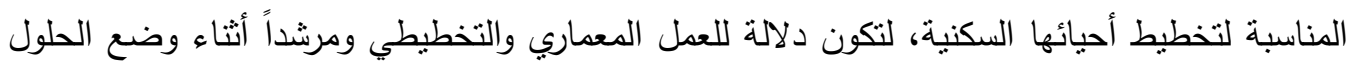

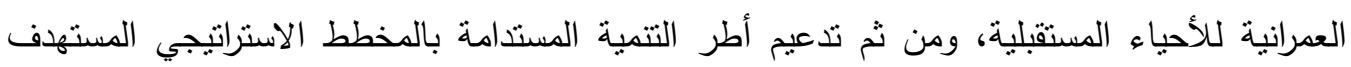
لمدينة الرياض حتى (عام 1442هـ). 


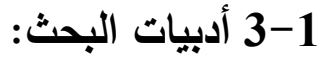

- من أهم الدراسات التي استهدفت "مشاركة الأبعاد البيئية في تخطبط الأحياء السكنية"، تلك الدراسات المصاحبة للمخطط الاستراتيجي الثشامل لمنطقة الرياض، حيث تعتبر من الخطوات العملية الفعالة التي

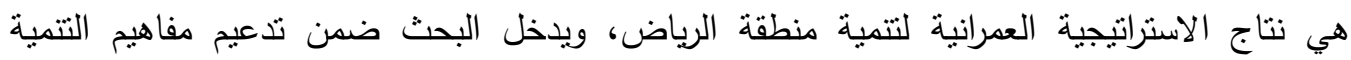

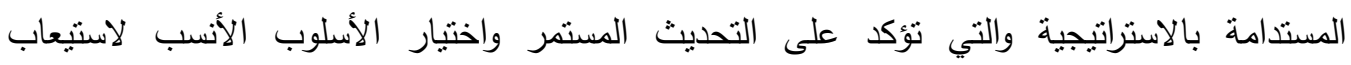
المستجدات والمتغيرات، وتفعيل آليات المراجعة للمخططات وبرامج التتمية بالمدينة، (الهيئة العليا لتطوير مدينة الرياض، عام 1424هـ، الموافق 2003 مدات ). - وفى دراسة استهدفت "تحسين كفاءة استخدام الطاقة في قطاع الأبنية" من خلال تحليل الخيارات في دول مختارة أعضاء الإسكوا (دول غرب آسيا)، ومن نتائجها تعاظم الطاقة المستتفذة في تكييف المباني بالأقطار العربية، وإمكانية توفير حوالي (30\%) منها في حالة مراعاة المعايير الخاصة بالأنماط

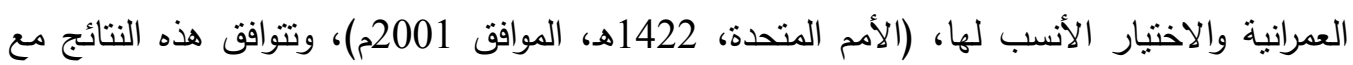
دراسة بعنوان "الفكر البيئي المستدام في تخطيط المناطق الصحراوية"، وتتاقش التخطيط البيئي للأحياء السكنية بمدينة القاهرة الجديدة بمصر ، وتركزت العملية الثقويمية على الأنساق العمرانية وأطر المعالجة التي بمقتضاها يمكن رفع كفاءة الأداء البيئي والعمراني بالأحياء السكنية بالمدينة. (أسامة خليل،

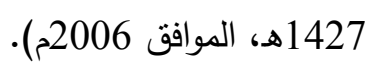

- ومن الدراسات التي استهدفت التأكيد علي دور المعايير البيئية في تثكيل عمران الددينة دراسة بعنوان "البعد البيئي في تخطيط وتصميم المدينة"، وذلك في ندوة الإبداع والتميز في النهضة العمرانية بالمملكة

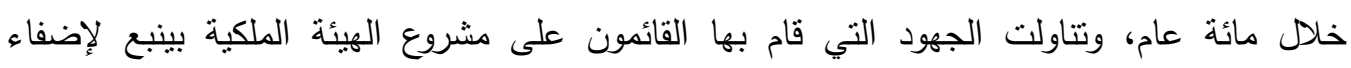
الثخصية البصرية على الفراغات الحضرية، ومزج العناصر الجمالية بالجوانب الوظيفية. (قصيران، عبد، 1423هـ، الموافق 2002م).

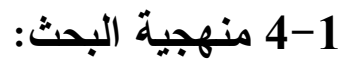

يعتمد البحث على عدة خطوات ومراحل منهجية تتأسس على الدنهج الوصفي، وتتتاول النظريات التي تعنى بمفاهيم الفكر البيئي المتوافق بالمدن الصحراوية بالمناطق الحارة، ويتم استخدام المنهج التحليلي

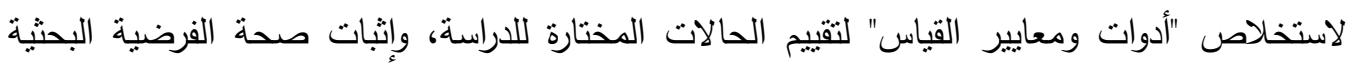
المطروحة، وتثم هذه العملية التقييمية من خلال دراسة تفصيلية لتأثير كل معيار على حدة، ودراسة كلية لتأثثر المعايير مجتمعة، والثكل رقم (1) يوضح مراحل وأنشطة البحث لتحقيق أهدافه. 


\section{ومف حسنسع البتثي.}

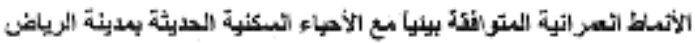

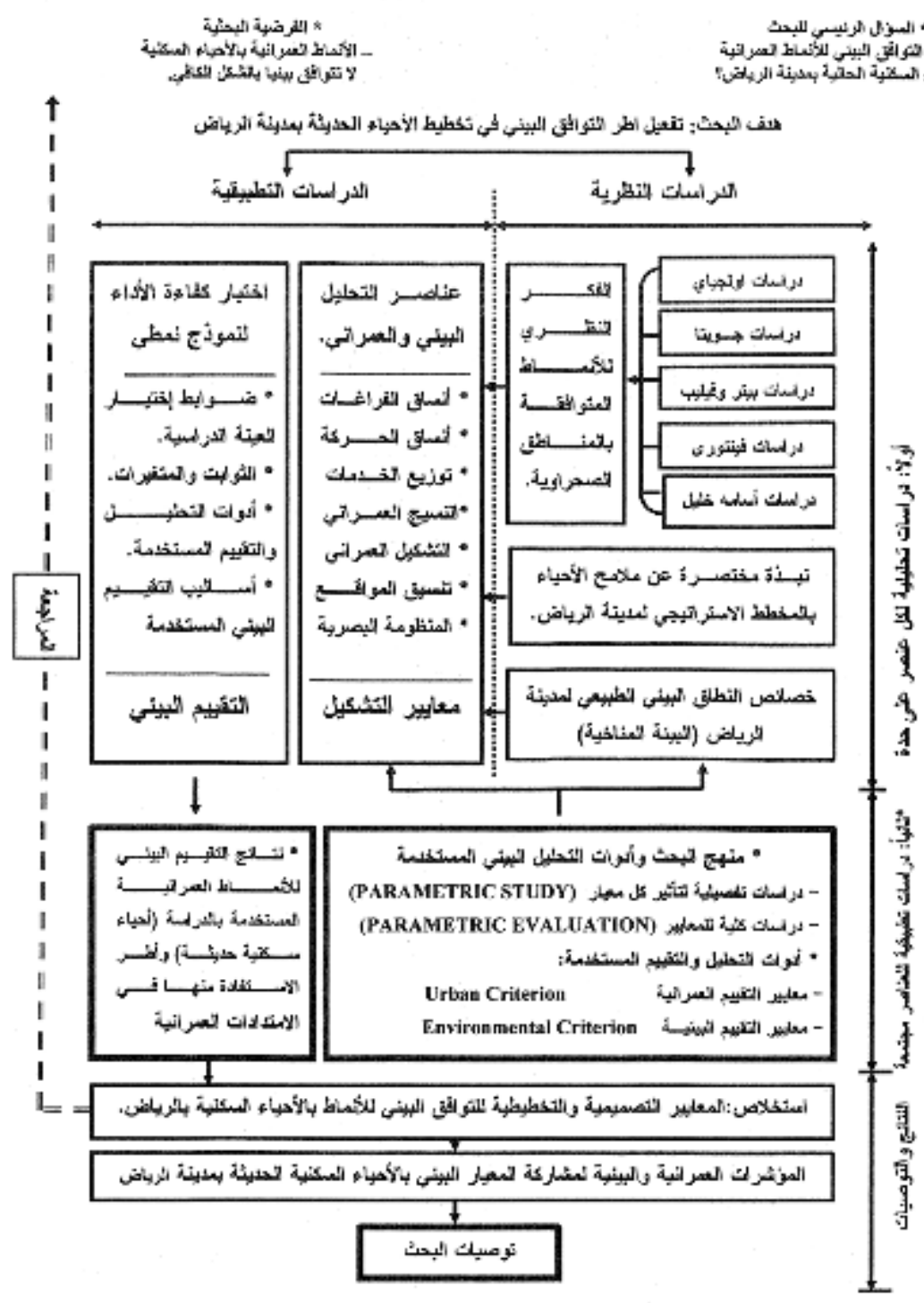

شكل رةم (') يوضيح مرأحل وأثنطة البحث 


\section{2- الأطر النظرية للتخطيط البيئي والعمراني بالأحياء السكنية}

- تتتكل المنظومة العمرانية الحاكمة للتخطيط البيئي والتشكيل العمراني بالأحياء السكنية من أربعة أنظمة بيئية رئيسية، تشمل البيئة الطبيعية والمشيدة والنظام الحيوي المحيط، والبيئة الاجتماعية للسكان وخلفياتهم الثقافية والحضارية، وبالطبع فان الأنماط العمرانية تمثل إحدى الأدوات العملية للتشكيل

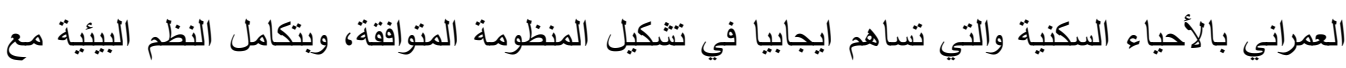
الأنماط العمرانية في إطار تقنيات العصر، فإنها سوف تكون منظومة موحدة تحقق الاستدامة وتعكس الهوية الوطنية.

\section{1-2 الأنماط النظرية للتشكيل العمراني بالأحياء السكنية}

تتثير الدراسات النظرية إلى ثلاث اتجاهات أساسية للتشكيل العمراني بالأحياء السكنية وهي (المركزي، والثريطي، والمنتشر)، وقد تم تصنيف هذه الاتجاهات إلى ستة أنماط عمرانية، لكل منها لـه مميزاته

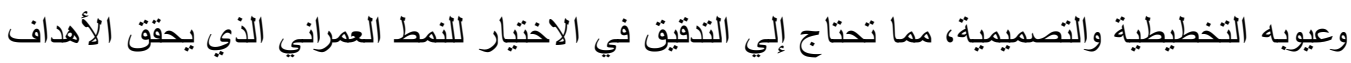

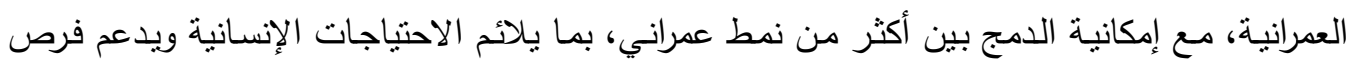

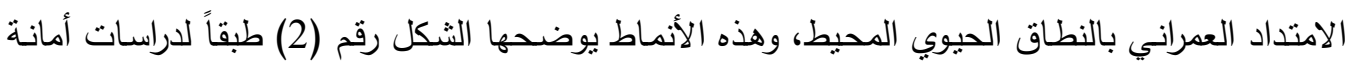

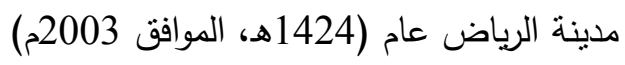

\section{2-2 العلاقة بين الأنماط العمرانية وتوظيف استخدام الطاقة بالأحياء السكنية.} - بتحليل معيار الطاقة والتخطيط بمقياس أصغر يتعاظم دوماً دور الطاقة ضمن مستوي وحدة الجوار

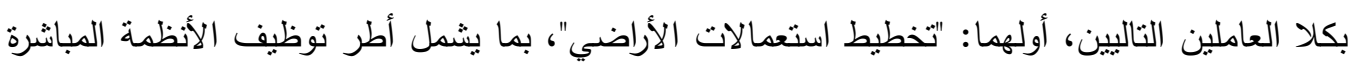

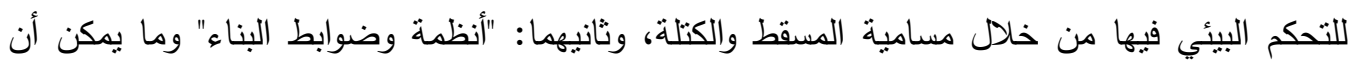
توفره العلوم التقنية والثورة المعلوماتية في هذا المجال، وهذه العناصر تتكل التكوين العمراني وأنماط

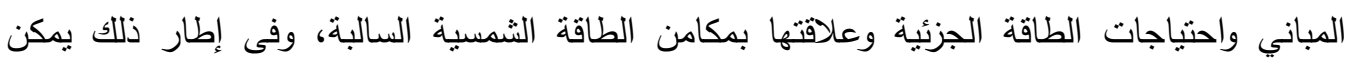
التحكم في البيئة الداخلية والخارجية وتصميم النسق العمراني البيئي المصغر على مستوى الوحدة والبلوك

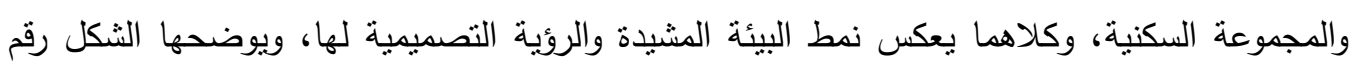




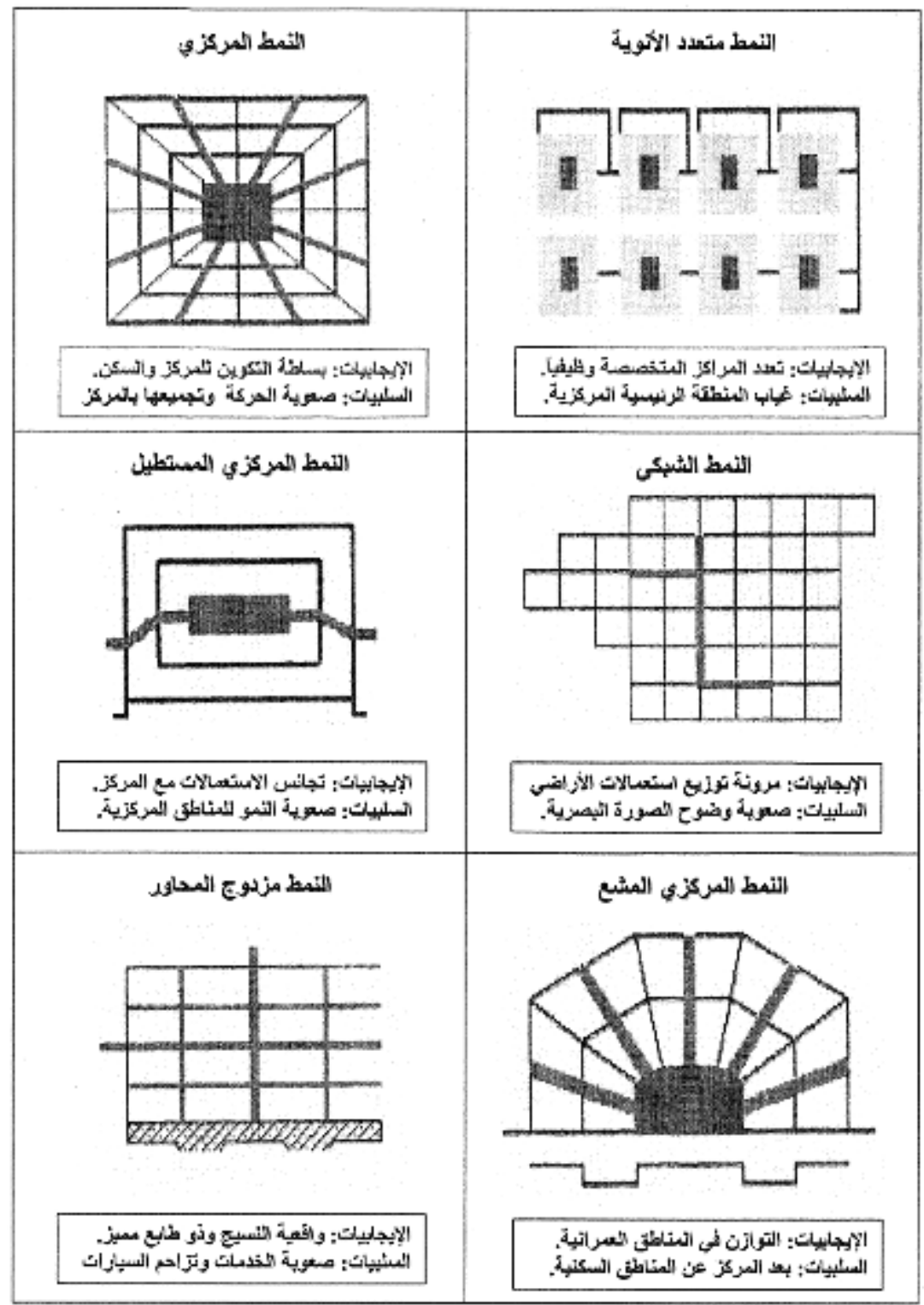

شكل رقم (r) الأنماط النظرية نتشكيل العمز أتبي بالأحباء السكثية.

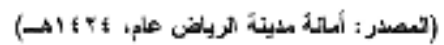

-i- 


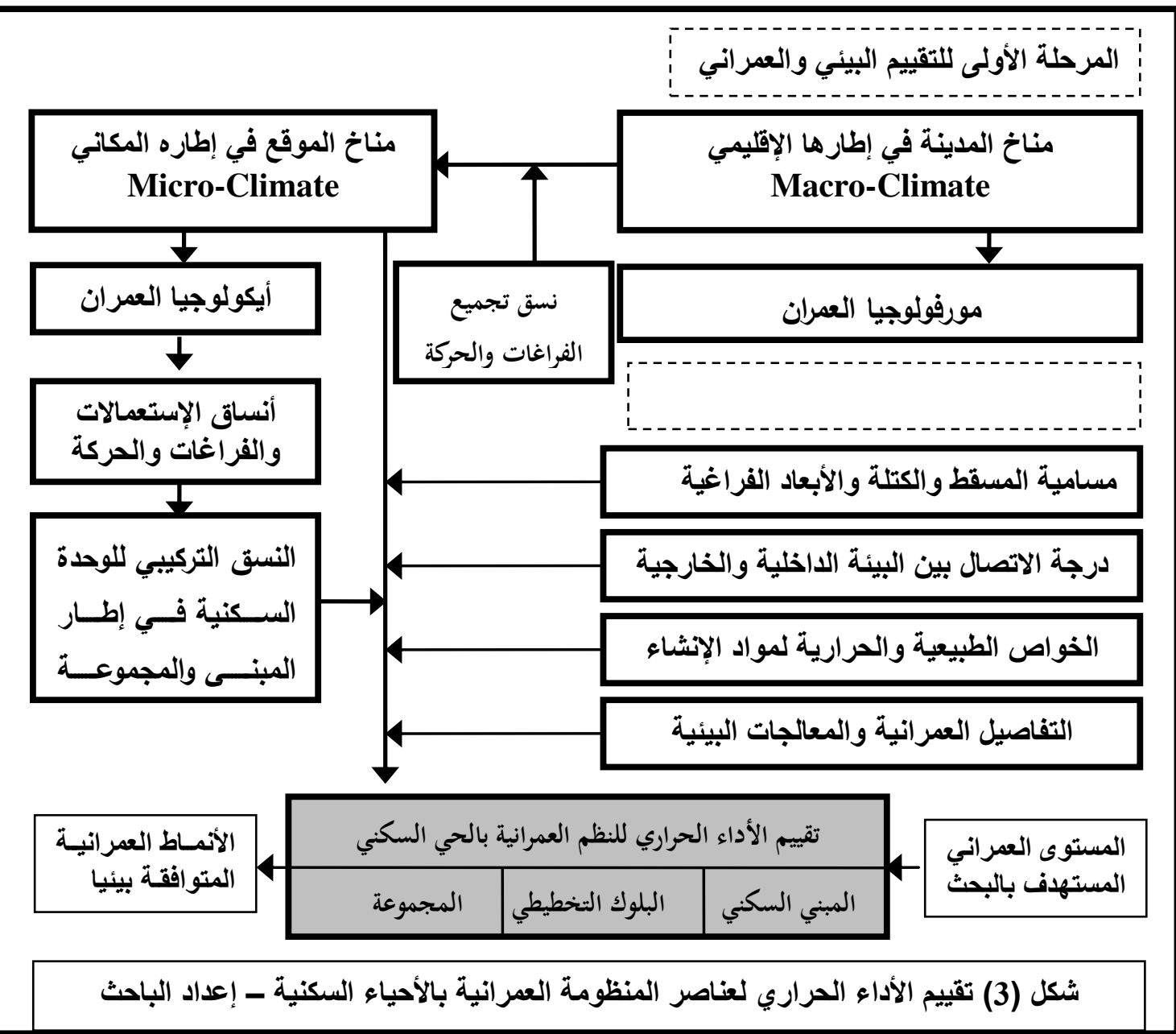

- ومن الناحية النظرية فقد أظهرت الحسابات أن المساكن المنفصلة تتطلب ثلاثة أضعاف الطاقة أكثر

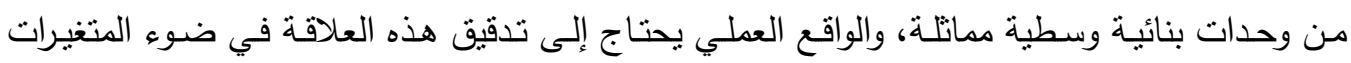

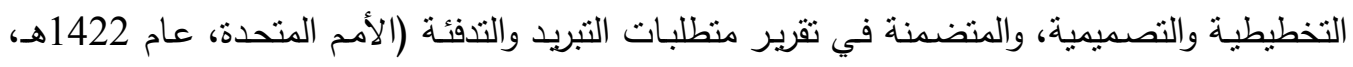
الموافق 2001))، وتؤكد ذلك دراسات (عساف 1422هـ، الموافق 2001م)، أن التكوين العمراني للسكن

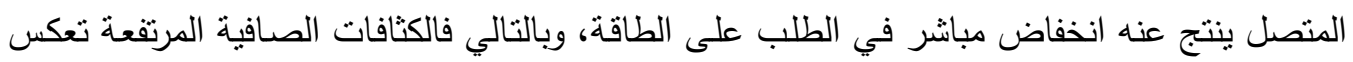

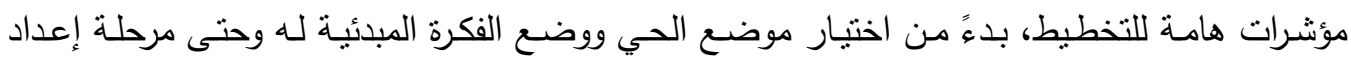
التصميمات التفصيلية للمشروع. 
2-2 طرق وأساليب التحكم البيئي في التشكيل العمراني بالأحياء السكنية.

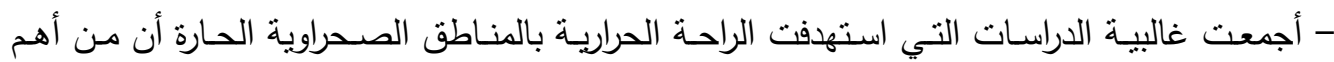

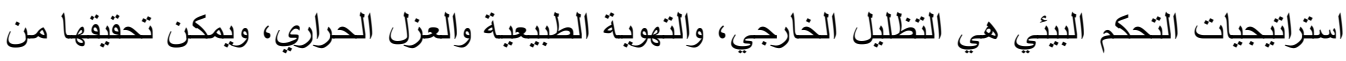

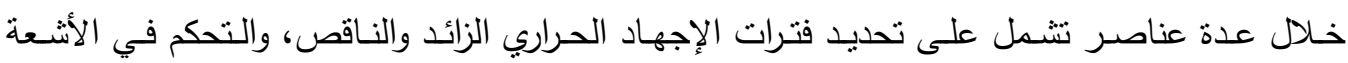

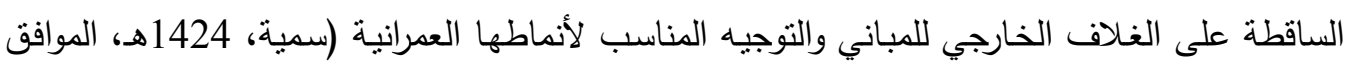
2003م)، والتحكم في الخصائص الحرارية للمواد المشكلة للغلاف الخارجي، ( الدليل الإرشادي للطاقة

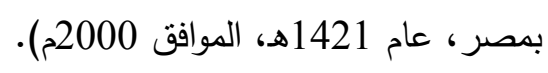

- يعتبر تتسيق الأحياء السكنية من أهم عناصر رفع كفاءة الأداء الحراري للأنماط العمرانية، بالإضافة

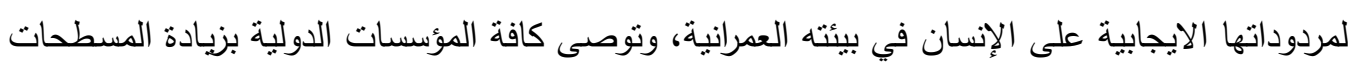

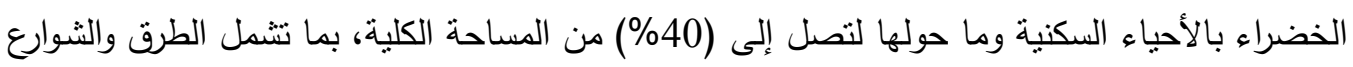

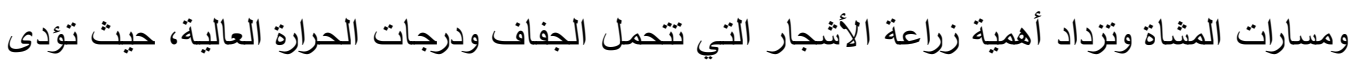

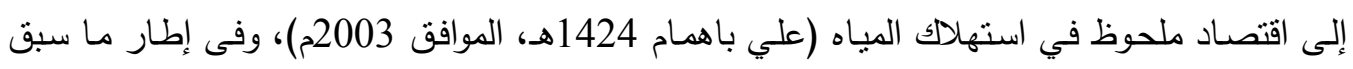

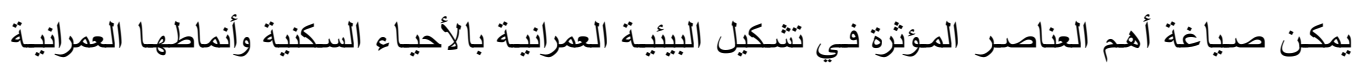
كالتالي:

\section{أولاً تشكيل الفراغات من خلال:}

- دراسة أنسب توجيه لزيادة أو منع وصول أنثعة الثمس للكتلة البنائية. - دراسة أنسب الفراغات التي نوفر الظروف الحرارية المريحة للإنسان. - توظيف مفردات عمرانية تعمل على زيادة كفاءة المبنى. - التتسيق الخارجي للفراغات العمرانية بما يلائم البيئة الطبيعية.

ثانياً: تشكيل الكتل والفتحات من خلال:

- دراسة الخواص الحرارية للمواد المشكلة للغلاف الخارجي للكتلة البنائية. - دراسة علاقة نسب الفتحات في الكتلة الخارجية المشيدة وتوجيهاتها الجغرافية. - دراسة علاقات التشكيلات البنائية وتعرضها للشمس، وبخاصة أثناء فترات الصيف.

* وهذه العناصر يناقثها البحث من خلال دراسات الباحثين في هذا المجال لتحديد مقدار المساهمة التي

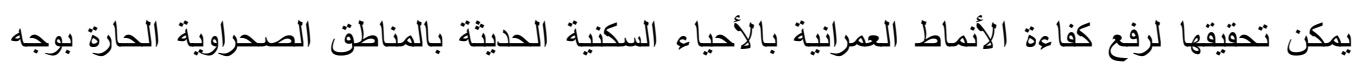
عام ومدينة الرياض بوجه خاص. 


\section{4-2 مناقشة دراسات استهوفت الأنماط العمرانية المتوافقة بيئياً}

- تعتبر دراسات (v. Olgyay, 1976) للبيئات المناخية المختلفة من أوائل الدراسات التي استهدفت

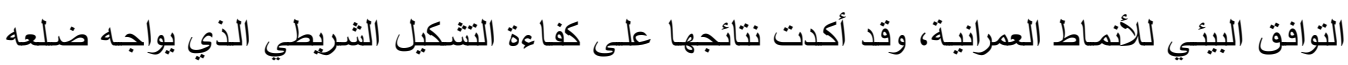
الأكبر اتجاه الثمال كنمط تخطيطي للمناطق الصحراوية الحارة، وبالنسبة للمناطق "الحارة الجافة" تسمح

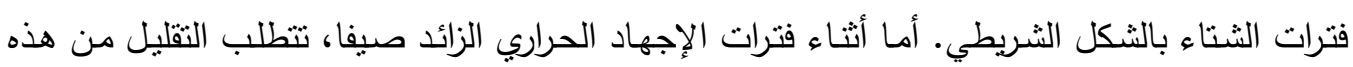
الاستطالة مرة أخرى لتصبح المباني أقرب إلى المربع، وتحقق النسبة (1 : 1.3) الحالة الأنسب، وتزيد إلى (1.6 1.6) في الحالات العملية، وتحتاج مباني هذه المناطق إلى تكوين فراغات داخلية تقوم بدور المنظم الحراري لهذه المباني.

- - وبالنسبة للمناطق "الحارة الرطبة" يؤثر سقوط أشعة الثمس على الجانبين (الثرقي والغربي)

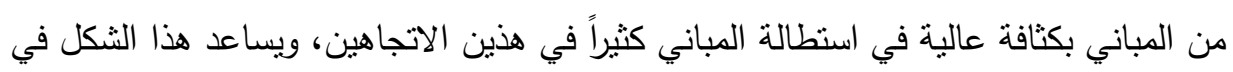

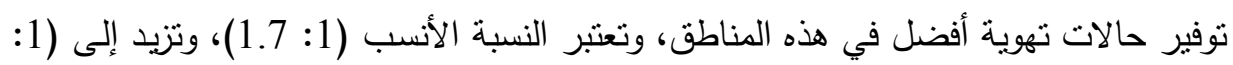
3) في الحالات العملية، ويمكن استخدام الثكل الحر مع توفير وسائل تظليل مناسبة للواجهات المعرضة لأشعة الثمس، والثكل رقم (4) يوضح هذه المؤشرات الرقمية.

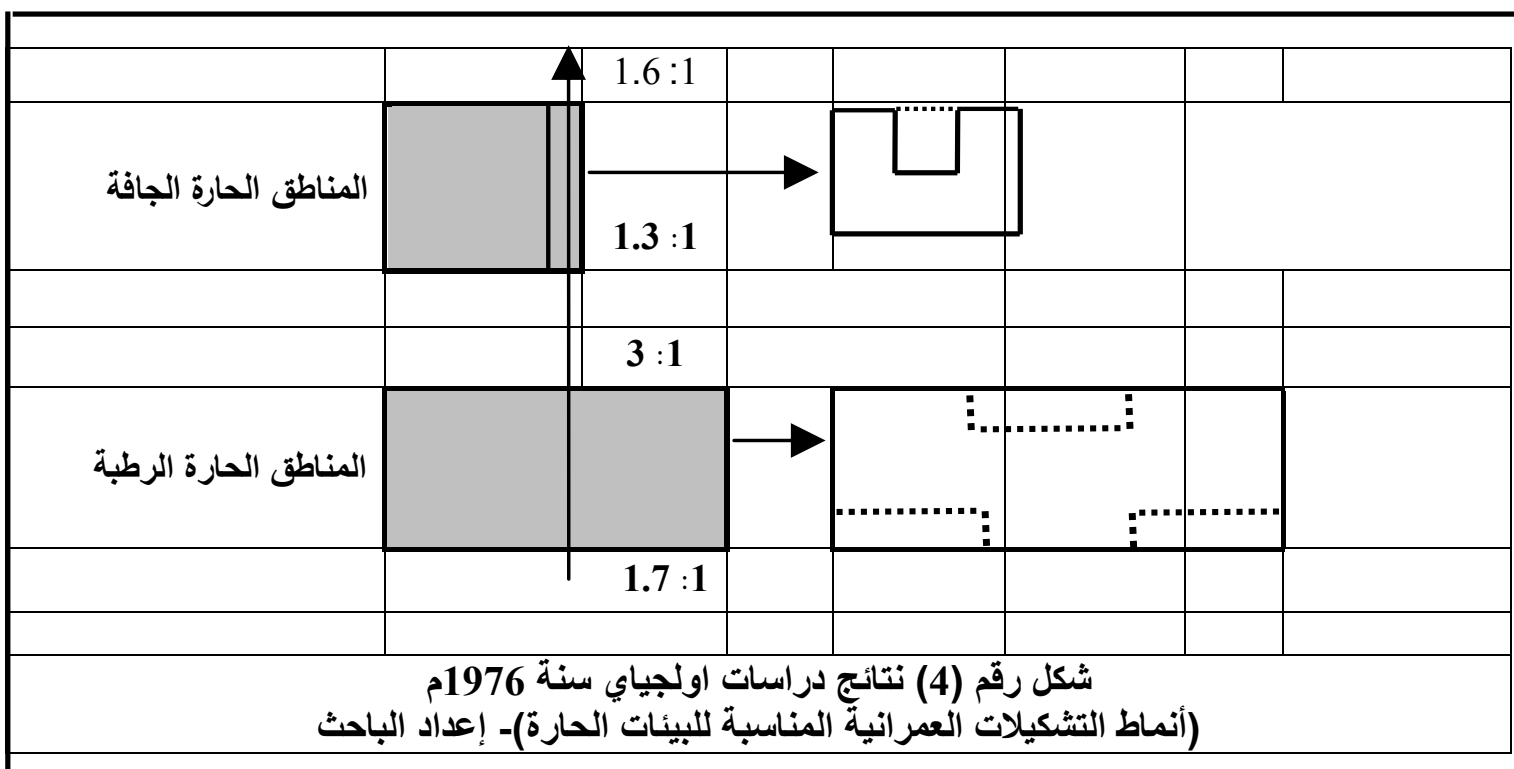

- - وأوضحت الدراسة التي أعدها (Gupta, 1986)، على أهمية رفع كفاءة الأداء للنمط الثريطي

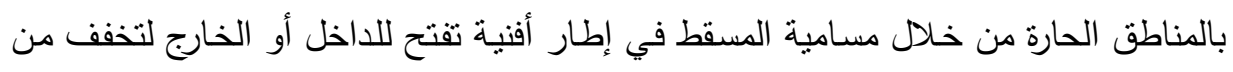
الإجهاد الحراري الزائد، وطورت هذه الدراسات بمعرفة (Peter \& Philip, 1987)، والتي 
أكدت على أهية التشكيل الخارجي للواجهات الثرقية والغربية من خلال الغلاف الخارجي لها، وتأتى في المرحلة الثانية بعد الإختبار الأنسب للتوجيه العام لتنكيل النسيج العمراني، بالإضافة التهات

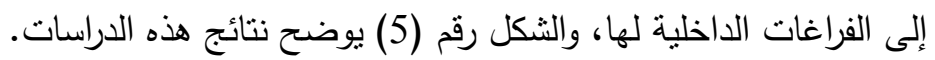

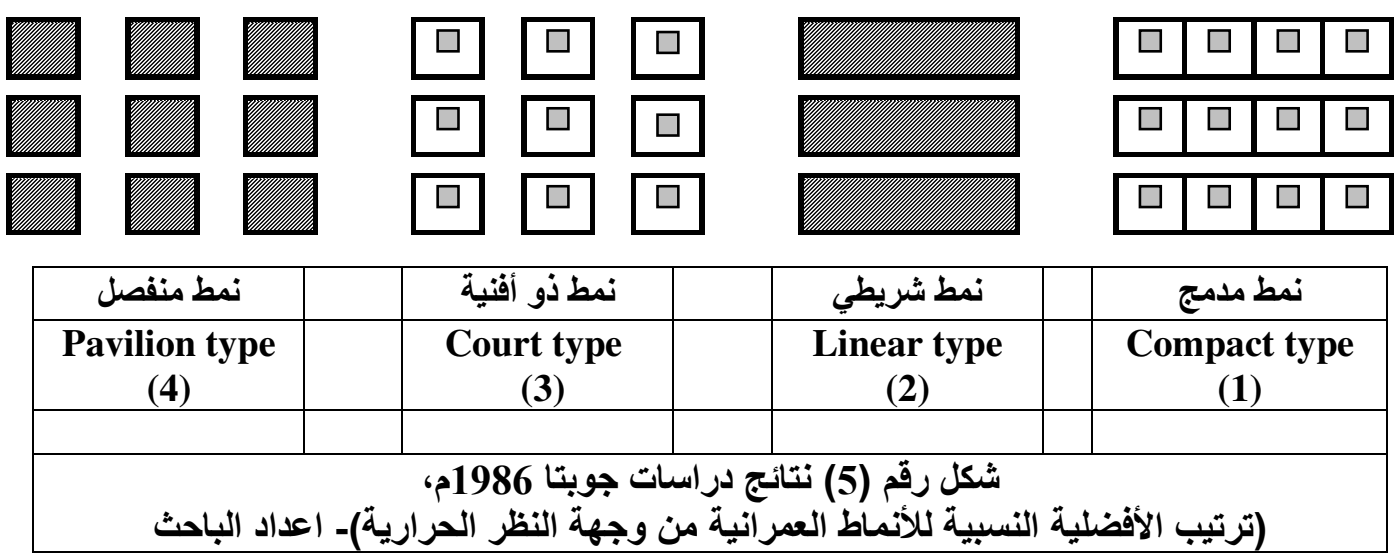

- وتتطابق هذه النتائج إلى حد كبير مع دراسات (سوزيت، 1989م)، والتي أوضحت النوافق النسبي

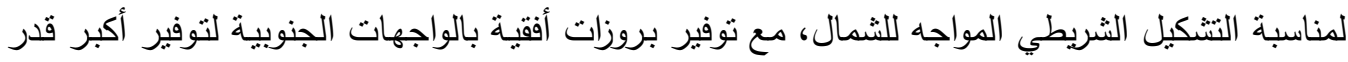
من الإظلال أثثاء فترات الإجهاد الحراري، ومن الدراسـات التي استهدفت تصميم الفراغات العمرانيـة بالأحياء السكنية التي أعدها (فنتورى، 1987م)، وأكدت على أهمية تصميم فراغ رئيسي يتوسط الكتلة

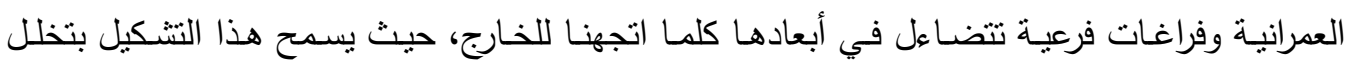

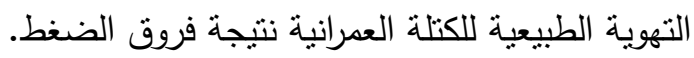
- وتتطابق هذه النتائج مع دراسـات (عساف، 2001م) لمدينة حلب بسوريا، والتي أوضحت مؤشراتها الرقميـة على تفوق النمط ذو الأفنيـة في توفير الطاقة بنسبة لاتقل عن (30\%ة)، وبخاصـة الأحمال

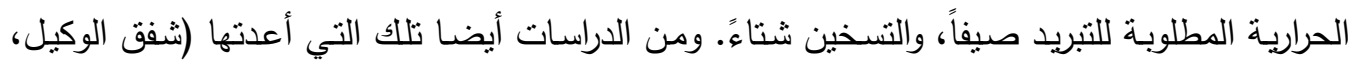

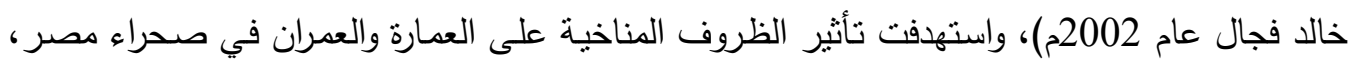
وإمكانية رفع كفاءة الأداء الحراري خلال عدة مجموعات سكنية بالمدن الجديدة، والثكل رقم (6) يوضح هذه النتائج.

- وفي دراسة استهدفت "تأثثر نتكيل الغـلاف الخارجي للمباني بالأحياء السكنية على الأداء الحراري

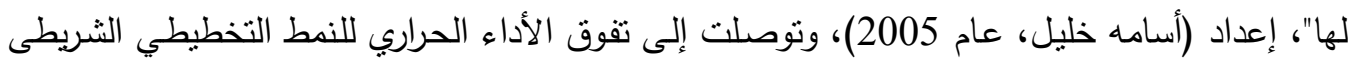

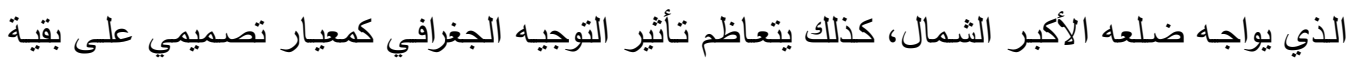


معايير نتكيل الغـلاف الخـارجي وتتمثنل مؤشـراتها في تأثثر التوجيه (44-48.5\%)، تأثنير الفتحـات

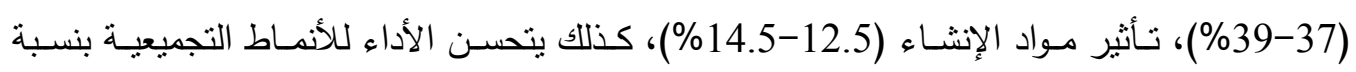
(50\%) في حالة زيادة الارتفاع من دور إلى ثلاثة، وهذه الدراسات نساهم في تقريب النتائج قدر الإمكان إلى الواقع العملي للبيئة السائدة بمدينة الرياض.
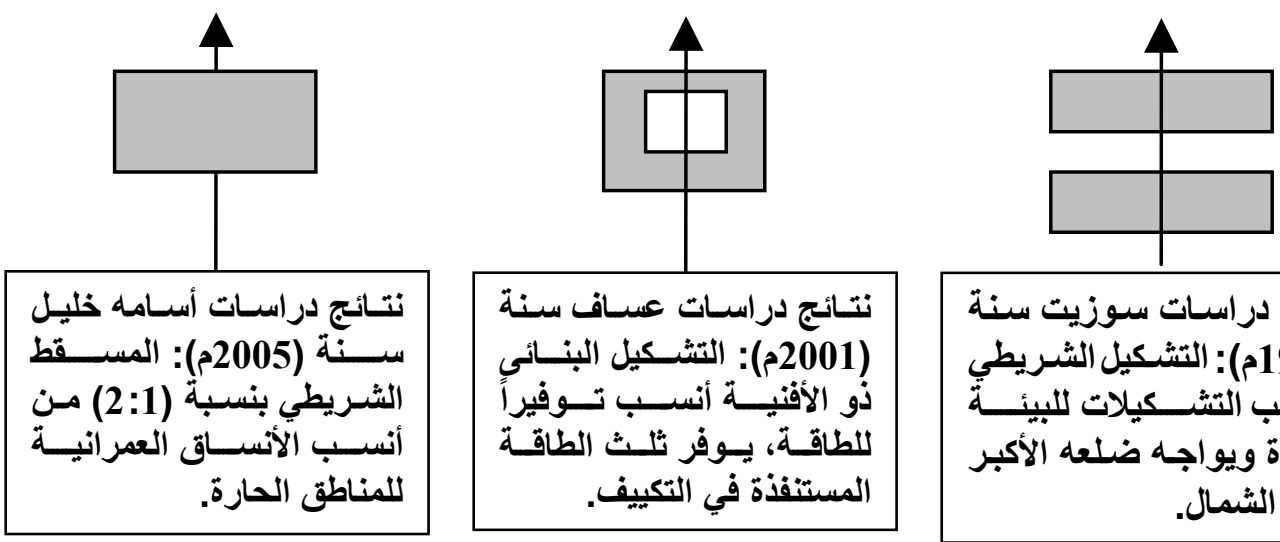

نتائج دراسـات سوزيت سنة

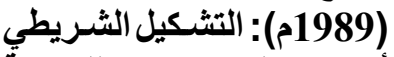

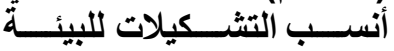

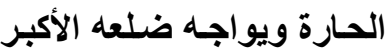

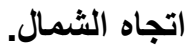

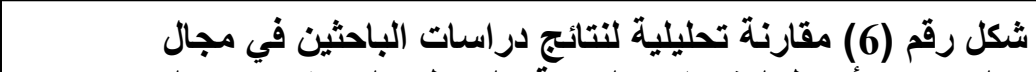
الأداء الحراري لأنماط التثكيلات البنائية بالمناطق درات الحارة- إعدادئ في الباحث

\section{3- خلفية عن مراحل تطور المخططات العمرانية لمدينة الرياض}

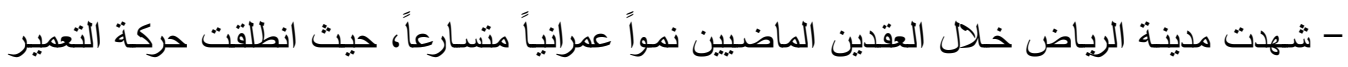

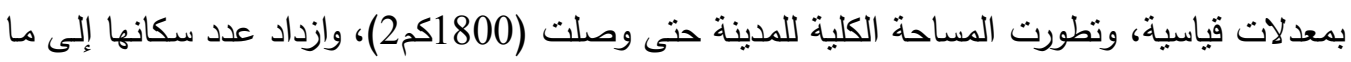

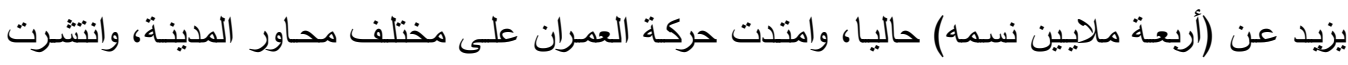
الأحياء الجديدة إلى ما وراء محيط الطريق الدائري فامتدت على الثمال الثرقي بنحو (18 اكم) بامتداد

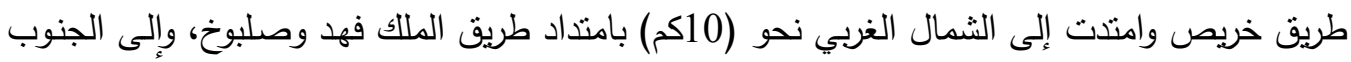

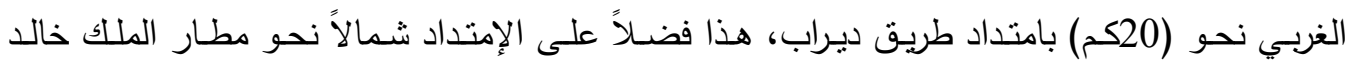
الدولي، وجنوباً نحو طريق الحائر ، وفى إطار هذه المؤشرات التتمويـة تم إعداد المخطط الاستراتيجي الإني للمدينة.

1-3 الروئة العمرانية لمدينة الرياض في إطار الإستراتيجية الوطنية. 
- جاء اعتماد الاستراتيجية العمرانية الوطنية بقرار مجلس الوزراء رقم (127) بتاريخ (1421/5/28هـ)

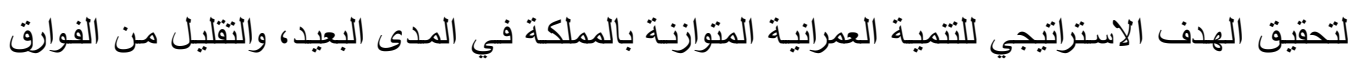

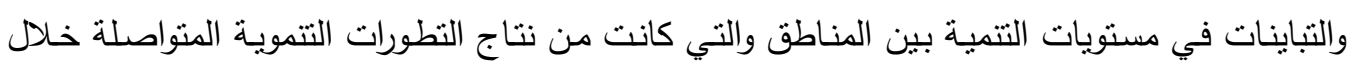

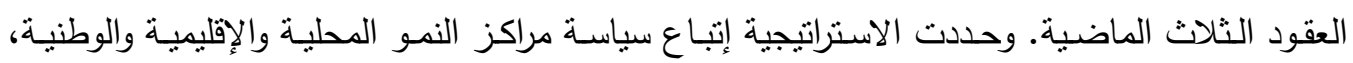

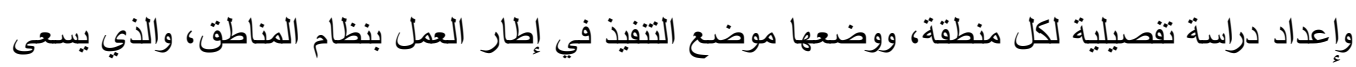

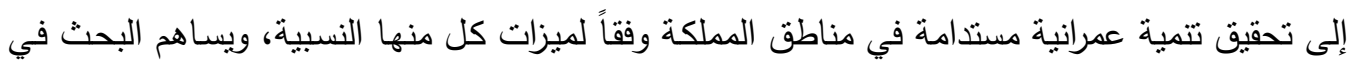
صباغة آليات النوافق البيئي للأنماط العمرانية باعتبارها من أدوات تحقيق النتمية المستدامة.

3-2 موجهات تخطيط الأحياء بإقليم الرياض حتى عام 1442هـ. - تم اعتماد المخطط الإستراتيجي لمدينة الرياض حتى عام (1442هـ)، والذي أكد على تفعيل مركز

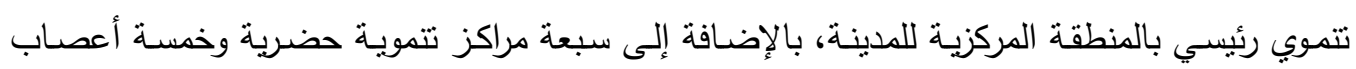

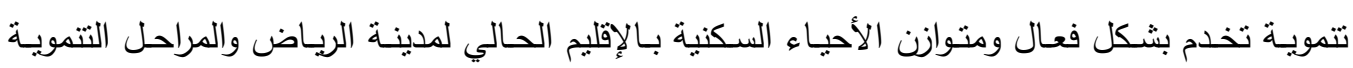

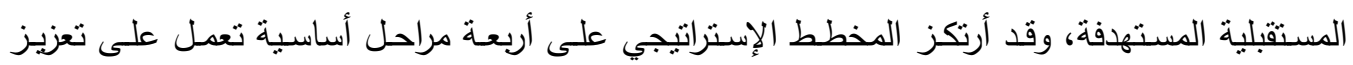

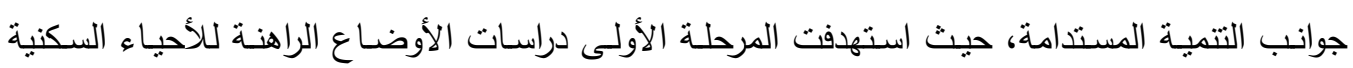
والنطاق الحيوي لها، آخذاً في الاعتبار الضوابط العمرانية المعمول بها، وتضمنت المرحلة الثانية والثالثة

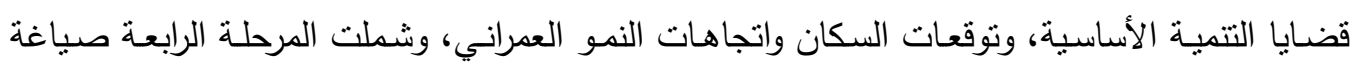

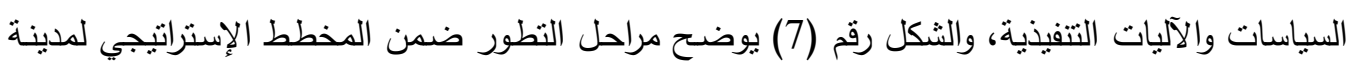
الرياض.

\section{3-3 النمط العام لتخطيط الأحياء السكنية الحديثة بمدينة الرياض}

- تتثكل الأحياء السكنية في مدينة الرياض من وحدات شبه نمطية في تخطيط شبكي متعامد، ومتوسط

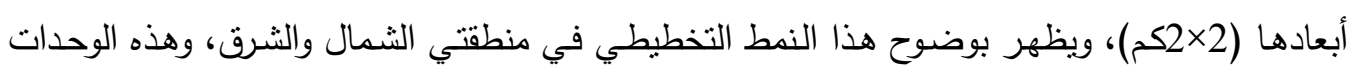
هي التي نتكل المخطط الإستراتيجي للمدينة وتحدد الروئة التتموية لأحيائها حتى عام (1442هـ)، وطبقاً

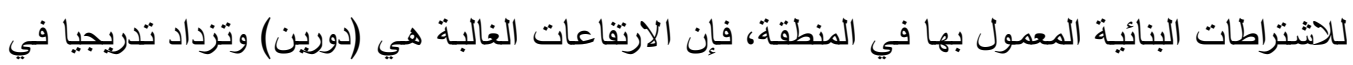
البلوكات التخطيطية المطلة على الثوارع الرئيسية. 

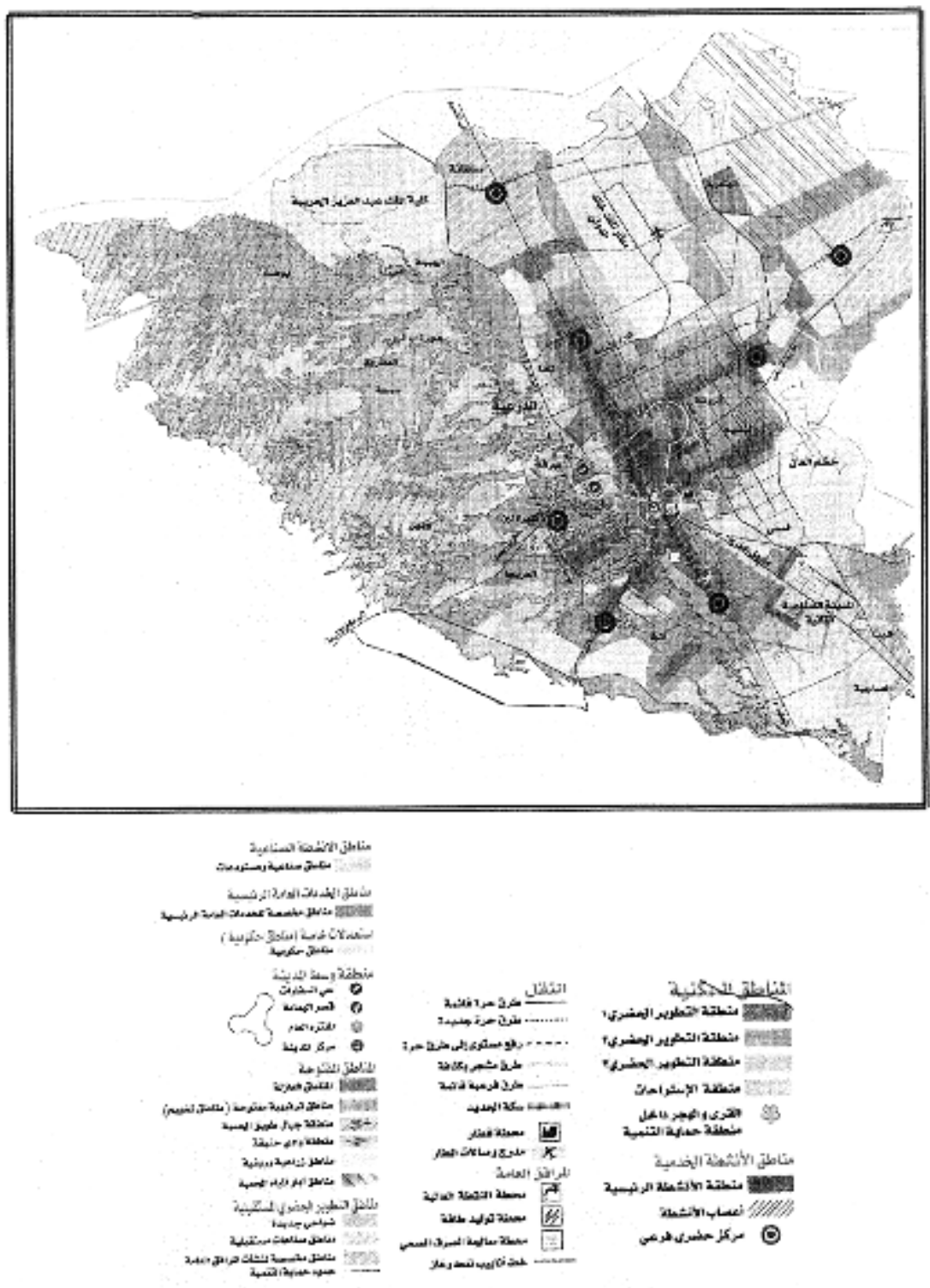

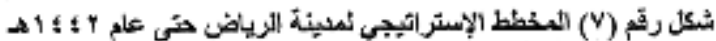

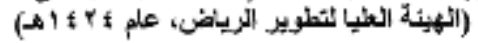


- وترتبط أنساق الحركة العمرانية في مدينة الرياض بشكل مباشر (طولياً وعرضياً) بنمو الأحياء السكنية

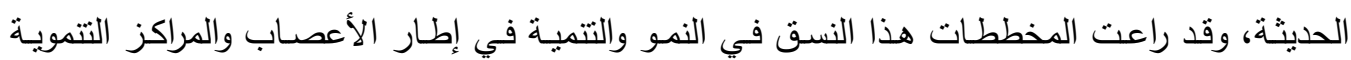

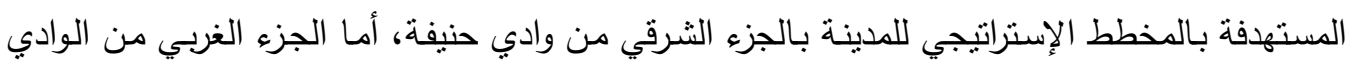

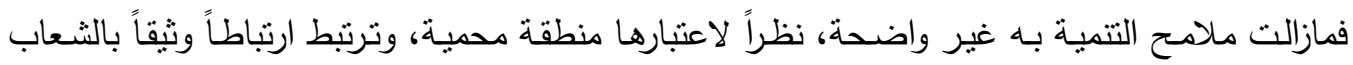
والتضاريس الطبيعية غرب منطقة الوادي.

\section{4- الخصائص البيئية الطبيعية لإقليم مدينة الرياض}

في إطار الأنظمة البيئية الطبيعية السائدة بإقليم الرياض، فان الدراسة بالبحث تتمل مستويين أولهما:

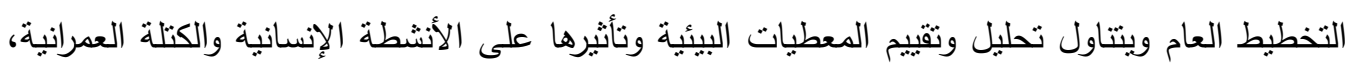

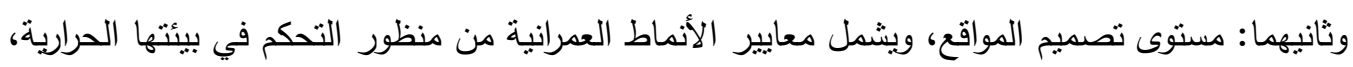

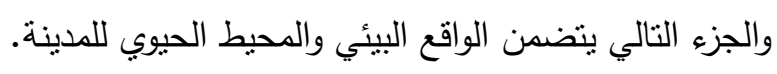

\section{4-1 النظام البيئي والحيوي المحيط بمدينة الرياض}

- تقع منطقة الرياض عند نقاطع خط عرض (24) شمالاً، وخط طول (47٪) شرقاً، والإقليم يدخل ضمن حدود المنطقة الصحراوية الحارة وشديد الحرارة، وتتشكل طبيعة تكوين المناطق العمرانية من أقاليم مناخية صغيرة يتراوح بعدها بين (3: 4 كم) من حدود المنطقة، وبالتالي يمند تأثيرها ليشمل محيطاً يعتمد أتساعه على حجم الكتلة العمرانية.

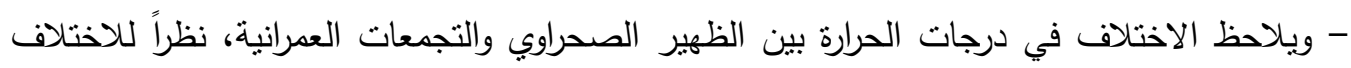

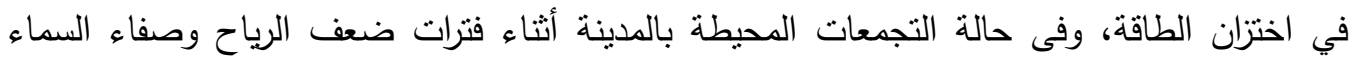
تتكون ما يعرف بالجزر الحرارية، حيث نقل درجة الحرارة في المناطق العمرانية عن الصحراوية المفتوحة

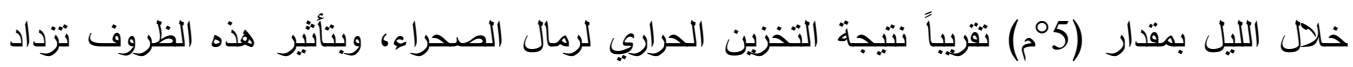

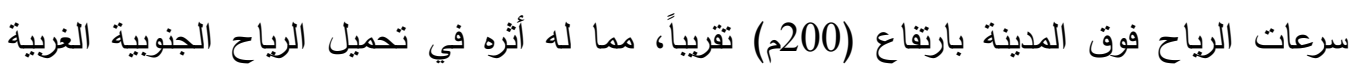
بالأتربة خلال شهري مارس وأبريل.

\section{4-2 تحليل المؤثرات المناخية لمدينة الرياض}

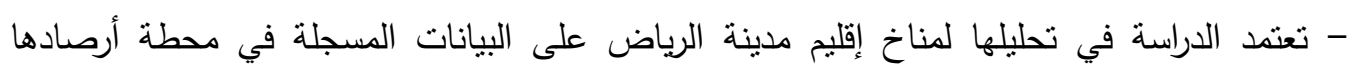

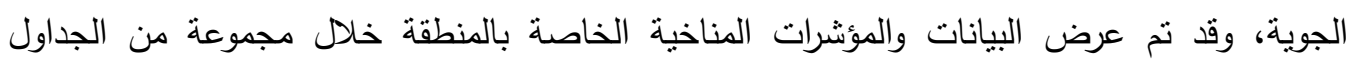

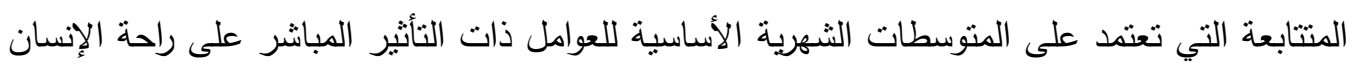

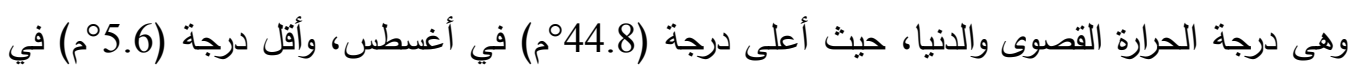


يناير ، ومنوسط درجات الحرارة القصوى على مدار اثشر العام (37 م)، والصغرى (19.6م) ومتوسط

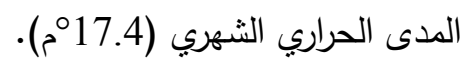

- وبالنسبة للرطوبة النسبية فإن موسطاتها نصل أدناها خلال شهري يونيو ويوليو (9-10\%) وذروتها خلال شهري يناير وديسمبر (47-50\%)، ومتوسطها السنوي (26.1\%)، وبالنسبة لكثافة الإثعاع

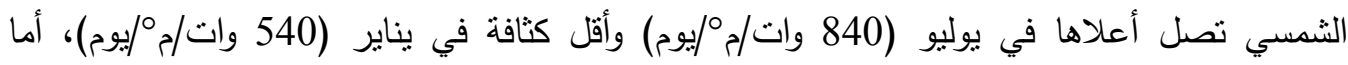

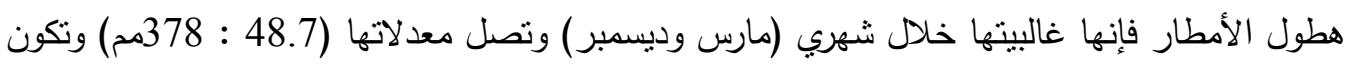
كمياتها محدودة خلال شهر إبريل وتصل (7.9مم). طبقاً للكتاب الإحصائي السنوي للمملكة عام

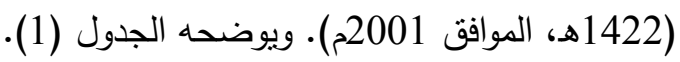

جدول رقم (1) مؤشرات البيئة الطبيعية المناخية لمدينة الرياض حسب الثهور

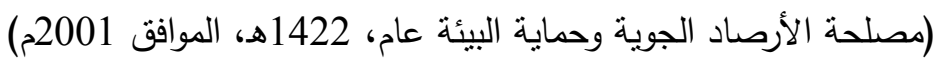

\begin{tabular}{|c|c|c|c|c|c|c|c|c|c|c|c|c|c|}
\hline \multicolumn{14}{|c|}{ متوسط درجات الحرارة (بالارجة المئوية) } \\
\hline |السنويط & 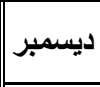 & نوفمبر & أكتوبر & سبتمبر & 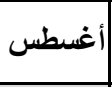 & يوليو & يونيه & 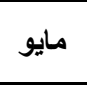 & أبريل & 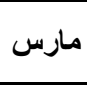 & فبراير & 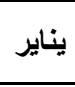 & الشهور \\
\hline 34.2 & 26.0 & 27.7 & 36.4 & 41.4 & 44.8 & 44.1 & 42.1 & 40.3 & 35.1 & 29.4 & 22.7 & 19.9 & متوسط درجات العظمي \\
\hline 18.1 & 13.1 & 11.9 & 18.3 & 24.0 & 28.0 & 26.9 & 25.0 & 23.2 & 18.5 & 14.7 & 8.1 & 5.6 & متوسط درجات الصغرى \\
\hline \multicolumn{14}{|c|}{ معدلات الرطوبة النسبية (نسبة مئوية) } \\
\hline 62 & 98 & 78 & 51 & 31 & 37 & 26 & 17 & 66 & 72 & 95 & 80 & 93 & أعلى درجة رطوبة \\
\hline 6.1 & 18 & 7 & 5 & 5 & 4 & 4 & 2 & 3 & 4 & 8 & 7 & 6 & أدنى درجة رطوبة \\
\hline \multicolumn{14}{|c|}{ اتجاه ومتوسط سرعة الرياح (الاتجاه طبقا لاتجاه البوصلة، والسرعة بالعقدة) } \\
\hline - & SSE & $\mathbf{N}$ & SSE & NNE & $\mathbf{N}$ & $\mathbf{N}$ & $\mathbf{N}$ & NNE & $\mathbf{S}$ & SSE & $\mathbf{N}$ & SE & اتجـاه الرياح \\
\hline 8.6 & 5 & 5 & 4 & 5 & 5 & 5 & 9 & 7 & 7 & 5 & 5 & 5 & متوسط السرعة \\
\hline \multicolumn{14}{|c|}{ أيام العواصف الرملية والرعدية والضباب حسب الشهور } \\
\hline- & $\mathbf{0}$ & $\mathbf{0}$ & $\mathbf{0}$ & $\mathbf{0}$ & $\mathbf{0}$ & $\mathbf{0}$ & $\mathbf{0}$ & $\mathbf{0}$ & 1 & $\mathbf{0}$ & $\mathbf{0}$ & $\mathbf{0}$ & العواصف الرملية \\
\hline- & 1 & $\mathbf{0}$ & $\mathbf{0}$ & $\mathbf{0}$ & $\mathbf{0}$ & $\mathbf{0}$ & $\mathbf{0}$ & $\mathbf{0}$ & 2 & 1 & $\mathbf{0}$ & $\mathbf{0}$ & العو اصف الرعاية \\
\hline- & $\mathbf{0}$ & $\mathbf{0}$ & $\mathbf{0}$ & $\mathbf{0}$ & $\mathbf{0}$ & $\mathbf{0}$ & $\mathbf{0}$ & $\mathbf{0}$ & $\mathbf{0}$ & 2 & $\mathbf{0}$ & $\mathbf{0}$ & الضبــاب \\
\hline \multicolumn{14}{|c|}{ هطــول الأمطـــار } \\
\hline م-ج) & 7 & $\mathbf{0}$ & $\mathbf{0}$ & $\mathbf{0}$ & 1 & $\mathbf{0}$ & $\mathbf{0}$ & 2 & 6 & 15 & 1 & 1 & عدد الأيـام \\
\hline مج(95) & 37.8 & $\mathbf{0}$ & $\mathbf{0}$ & $\mathbf{0}$ & $\mathbf{0}$ & $\mathbf{0}$ & $\mathbf{0}$ & $\mathbf{0}$ & 7.9 & 48.7 & 1.1 & $\mathbf{0}$ & كمية الأمطار (مم) \\
\hline
\end{tabular}

المصدر: الكتاب الإحصائي السنوي، عدد(37) سنة 2001م

- وبذللك تعتبر الفترة من (نوفمبر إلى مارس) معتلة نسبياً، أما شهري (بوليو وأغسطس) فإنها شديدة

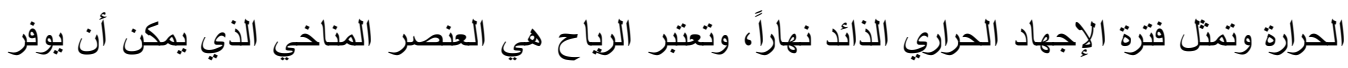


الراحة خلال هذين الثهرين، بالإضافة إلى البخر ، أما المجال البارد ينحصر فى الليل من (نوفمبر إلى

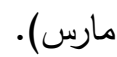

1-2-4 تأثير الإشعاع الثمسي على الأنماط التخطيطية بمدينة الرياض - من خلال تصنيف المجالات المناخية لمدينة الرياض، وبحساب التوجيه المرغوب في فترة الصيف،

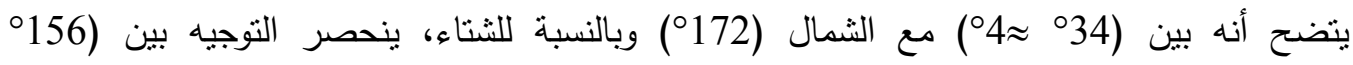

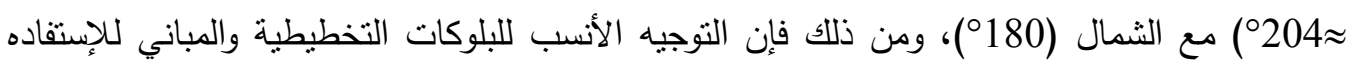
القصوى من الإثعاع الثمسي لأطول فترة ممكنه يكون مواجه للثمال، ومحوره الطولي يميل بزاوية

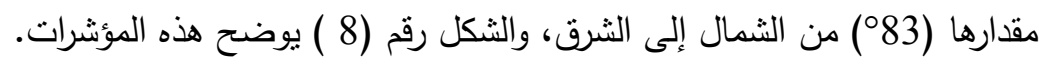

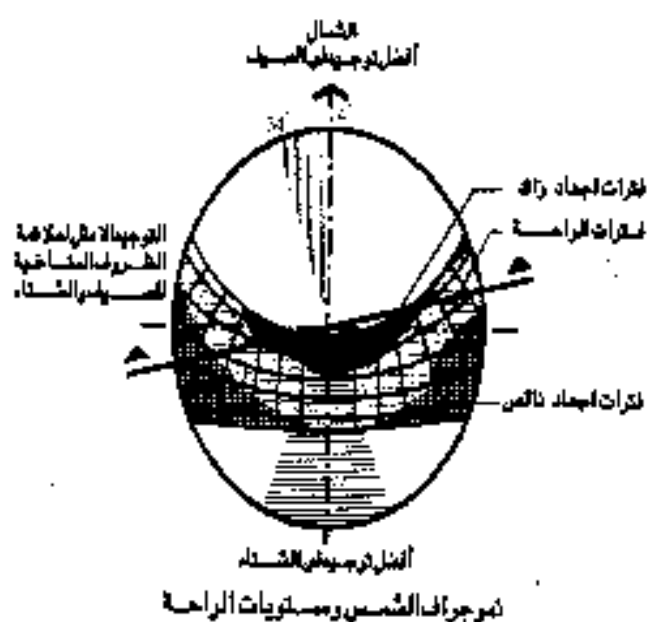

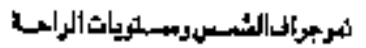

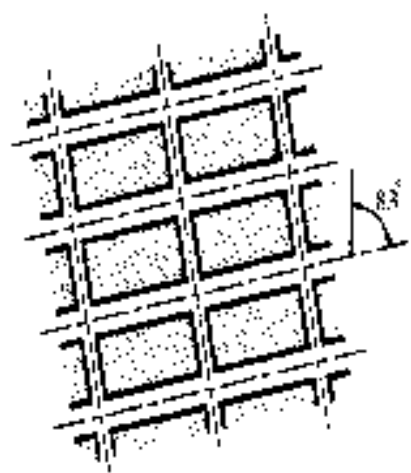

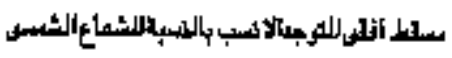
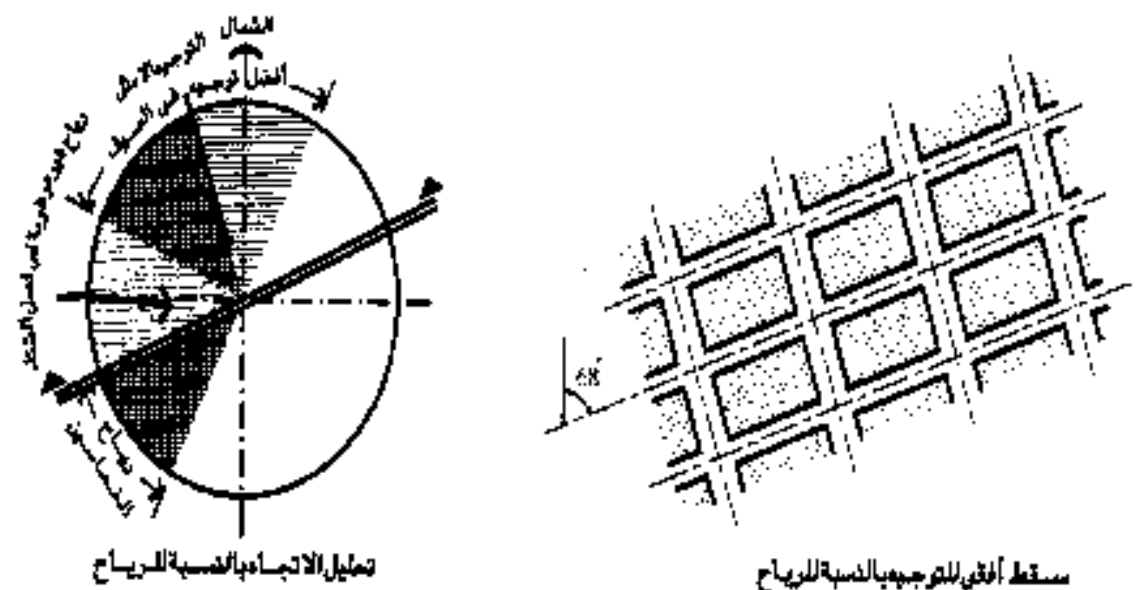

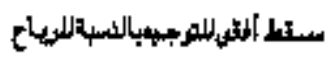

شكل (8) مؤشرات التوجيه الأنسب بالنسبة للشمس والرياح بمدينة الرياض- إعداد الباحث 
2-2-4 تأثير سلوك الرياح خلال النسيج العمراني لأحياء مدينة الرياض - تختلف حركة الهواء خلال المناطق العمرانية، عنها في المناطق الصحراوية المفتوحة والمستوية، فالرياح تتفاعل مباشرة مع الأثكال الهندسية المكونة للنسيج العمراني، وتتأثر بالقوى الحرارية المتولدة،

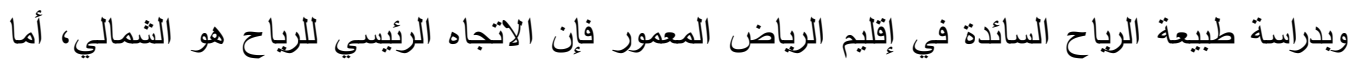

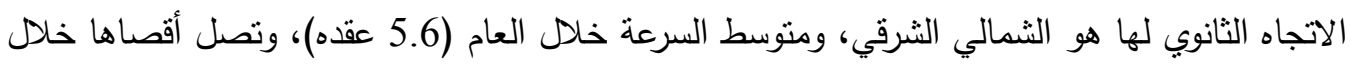
شهر يونيو (9 عقدة). - أما بالنسبة لرياح الخماسين فإنها تهب من الهن الجنوب الغربي محملة بالرمال والأتربة من الظهير

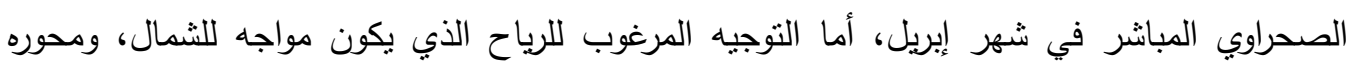

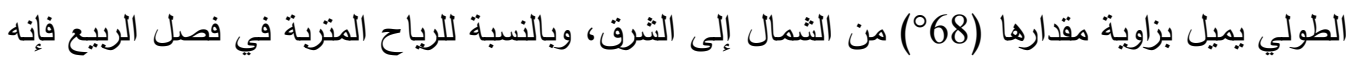

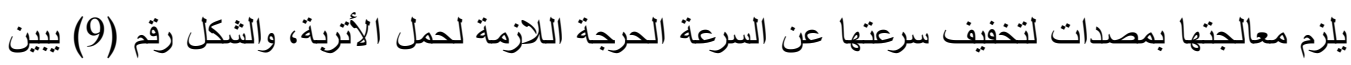
الاتجاهات المرغوبة للرياح بالنسبة لمدينة الرياض.

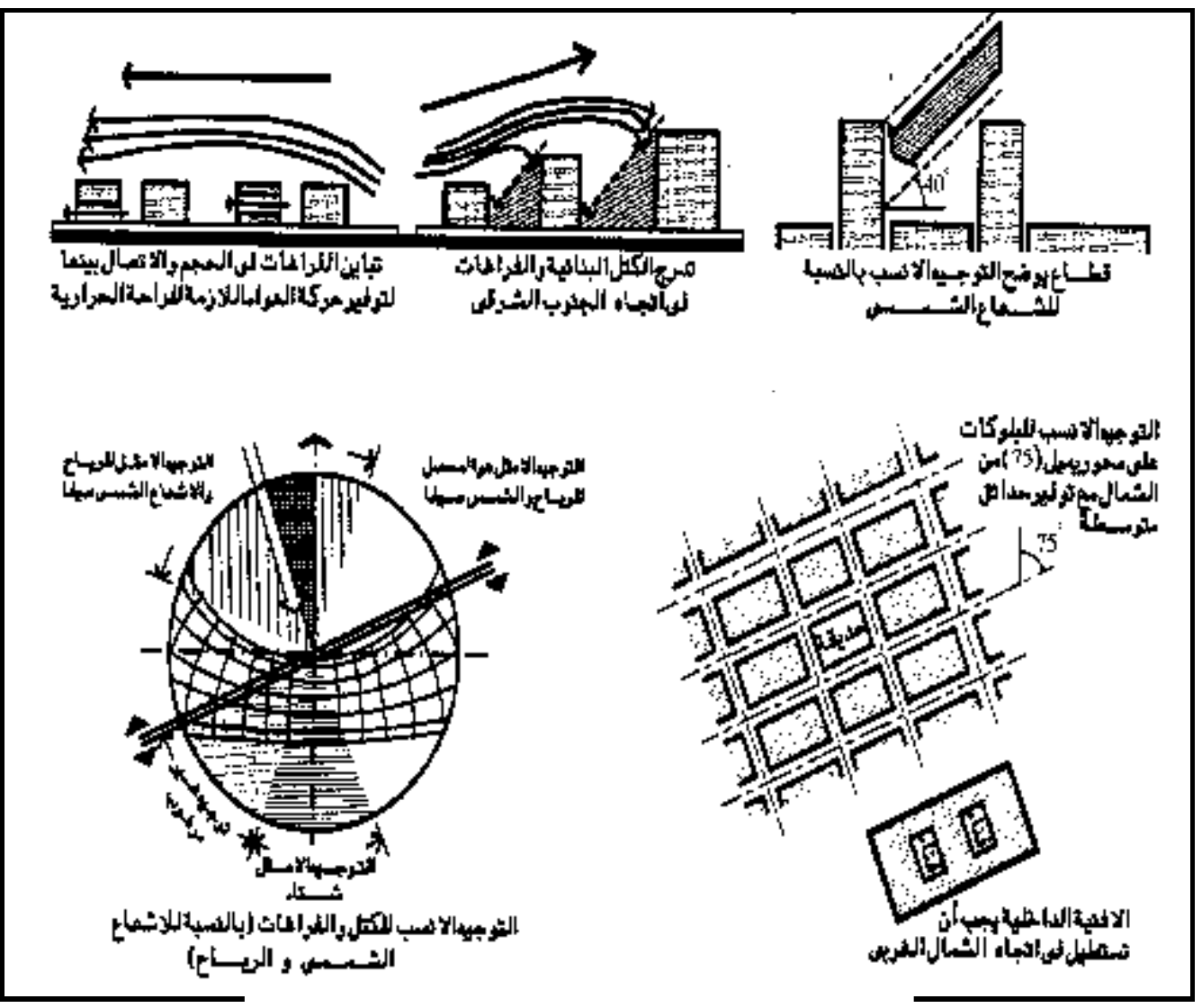

شكل (9) مؤشرات التوجيه الأنسب للنمط التخطيطي بالأحياء السكنية بمدينة الرياض- إعداد الباحث 


\section{4-4 الضوابط البيئية لاختيار الأنماط العمرانية بمدينة الرياض.}

- يتشكل النموذج المقترح للبلوكات التخطيطية بالأحياء السكنية من محصلة التوجيه الأنسب للرياح

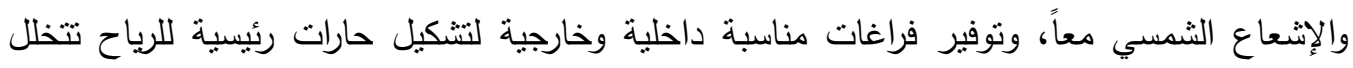

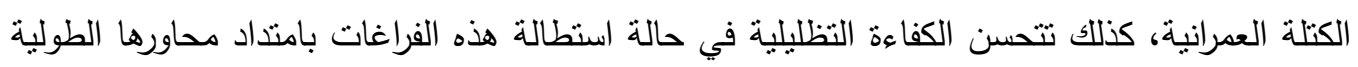

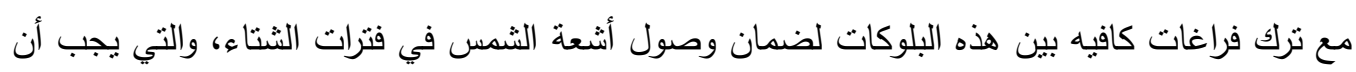
لاتقل زاوية ميالها شتاءً عن (40))، كما يفضل أن نستطيل الكتلة البنائية عمودياً على اتجاه الرياح

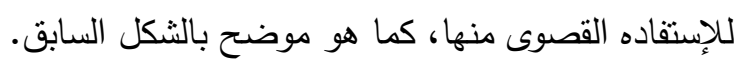
- وبتطبيق الضوابط البيئية الحرارية، يمكن صياغة النموذج العمراني في نتكيل شريطي يمند محوره الطولي في اتجاه (شمال شرق/جنوب غرب) ويميل بزاوية مقدارها (75º في اتجاه (الثمال شرق)،

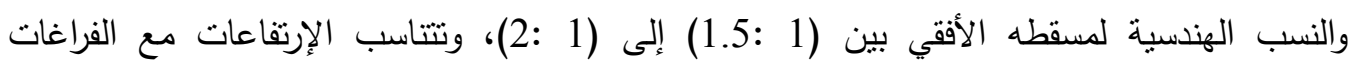
والثوارع بنسبة (1 :2)، والثنكل (10) يوضح النموذج الإرشادي.
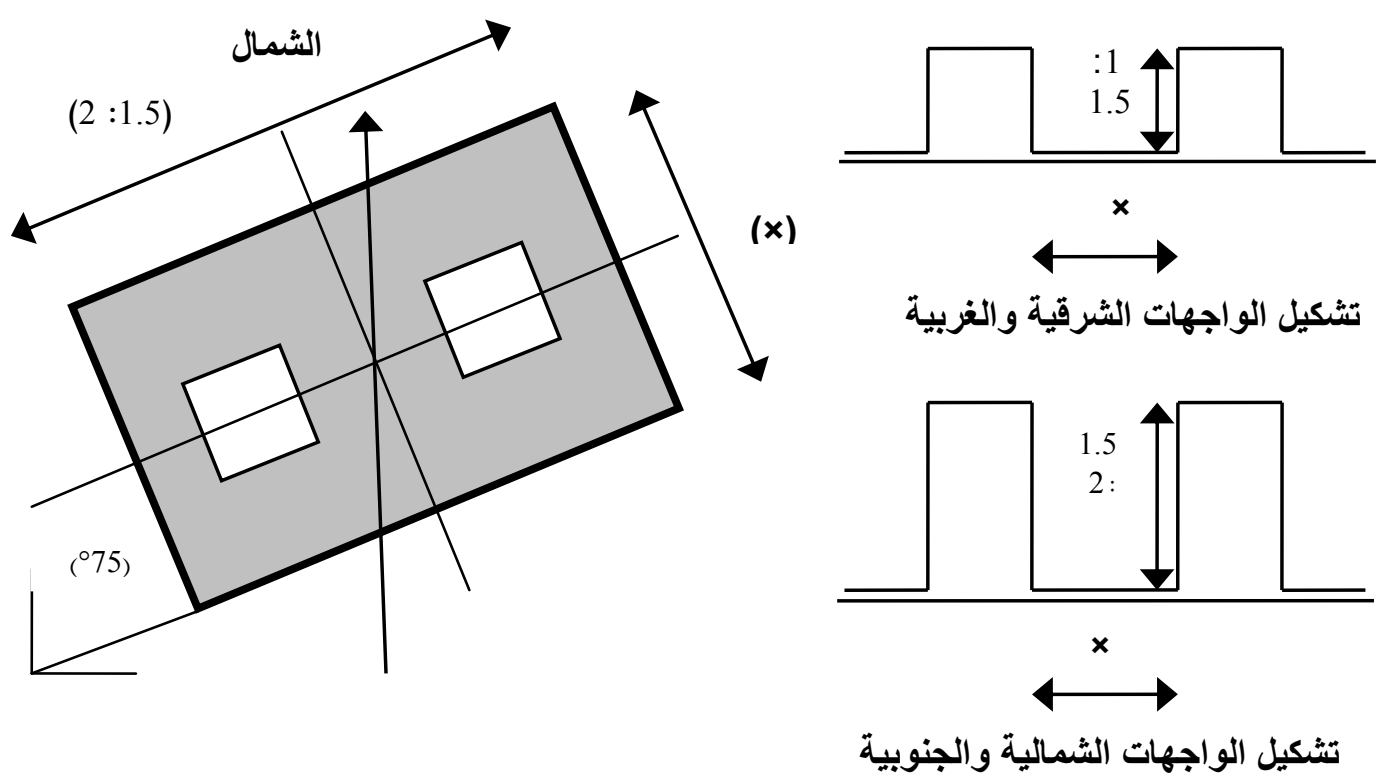

مورفولوجية المسقط الأفقي:

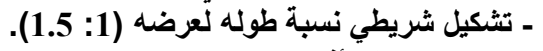
- يميل المسقط الأفقي (75) من الثمال للثرنة
الأبعاد الفراغية للكتلة:

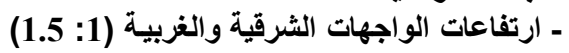
- ارتفاعات الواجهات الثمالية والجنوبية (1.5 : 2 : 2 الثنات

شكل رقم (10) النموذج العمر اني المقترح لمدينة الرياض طبقاً لاراسات البحث - إعداد الباحث 


\section{5- تقييم الأداء البيئي لنماذج مختارة من أحياء سكنية حديثة بمدينة الرياض}

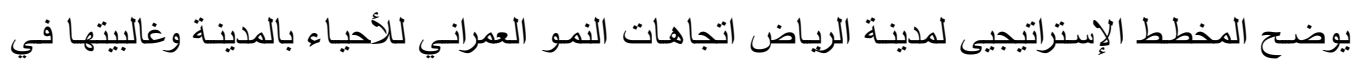

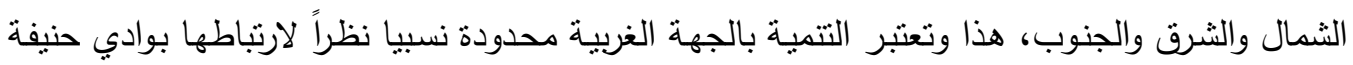
واعتبارها منطقة شبه محمية، وبناء على هذه المحددات فقد تم اختيار ثناث أحياء سكنية حديثة، وهي

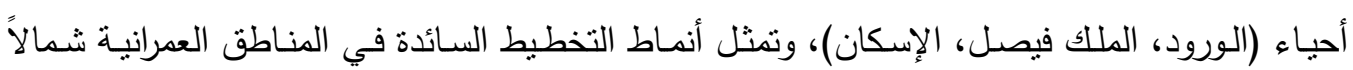
وشرقاً وجنوباً على التوالي في مدينة الرياض.

\section{1-5 أسباب اختيار الأحياء السكنية مجال الدراسة:}

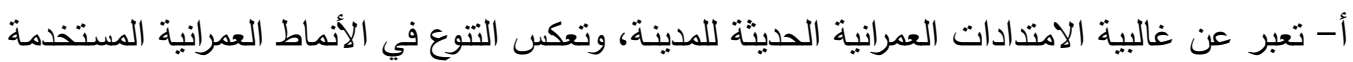
في ضوء دراسات البحث النظرية والميدانية. ب- مراعـاة التخصص الـوظيفي للأحيـاء المختارة للدراسـة، وتكـون ضـمن المخططسات المعتمدة مـن

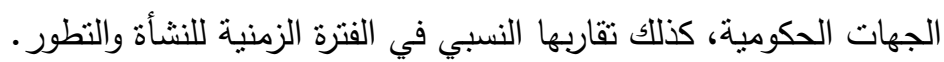

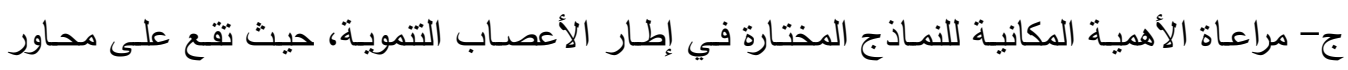
رئيسية ضمن المخطط الإستراتيجي الثامل لمدينة الرياض حتى عام (1442هـ).

\section{5-2 تحليل الوضع العمراني والبيئي للأحياء مجال الدراسة.} - نطورت واستقرت أحياء (الورود والملك فيصل والإسكان) ضمن المخطط الإستراتيجي لمدينة الرياض،

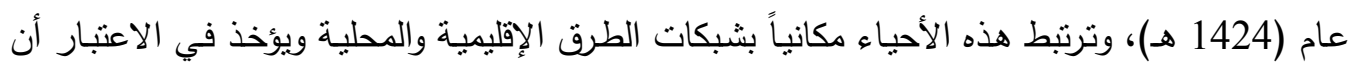

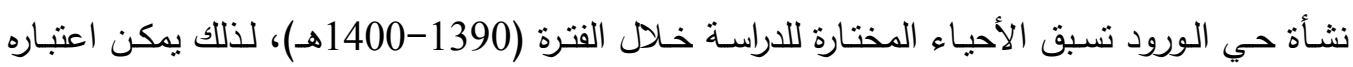

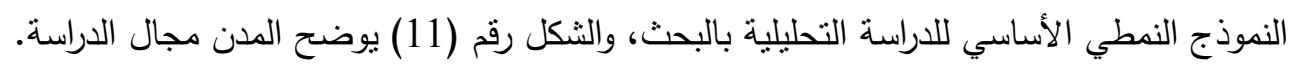

$$
\text { 5 -2-5 حي الورود: }
$$

- يقع حي الورود في شمال مدينة الرياض ويتبع بلدية العليا، ويحده من الجهة الثمالية طريق الملك

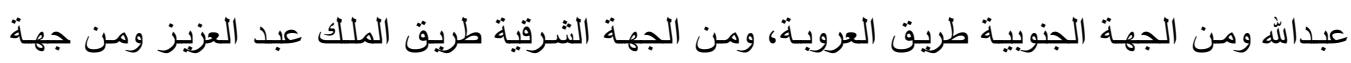
الغرب يحده طريق العليا، وتبلغ مساحة الحي (400 هكتار) والمسقط الهندسي له على شكل مربع نقريباً وهو نموذج نمطي ينشابهه إلى حد كبير مع أحياء السكنية عديدة في محيطه المكاني، وبخاصة أحياء الملك فهد والمروج في الجهة الثمالية للمدينة، والفكر التخطيطي العمراني للحي يتأسس على ألى أربعة

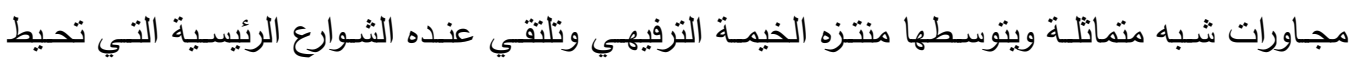




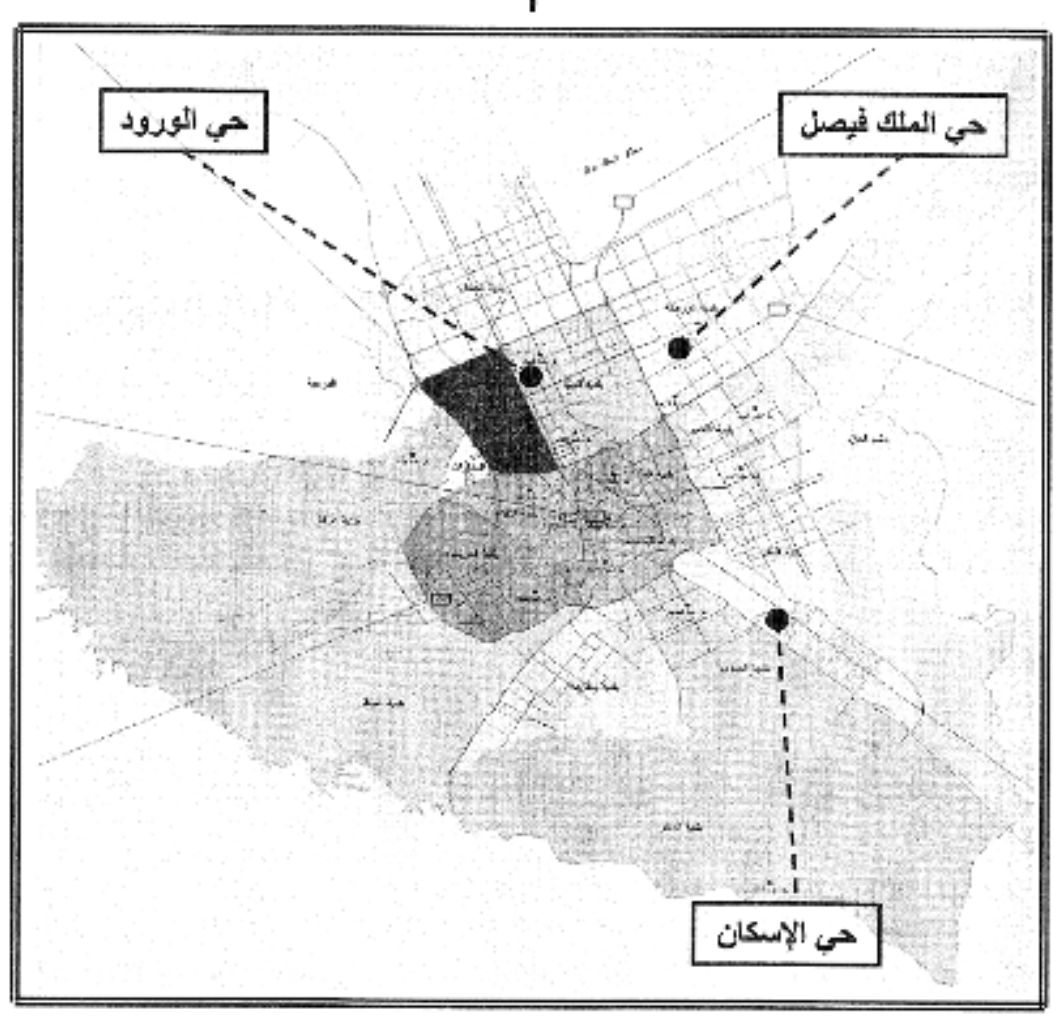

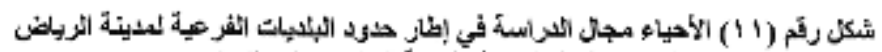

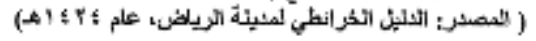

- والثـكل الهندسي للموقع العـام لــي الـورود يميل محسوره الرأسـي باتجـاه الثـــال الغربـ، وتتركز الإرتفاعات على الطرق الرئيسية من (3 : 6 أدوار) أما غالبية مباني الحي الداخلية فتتراوح بين (2: 3

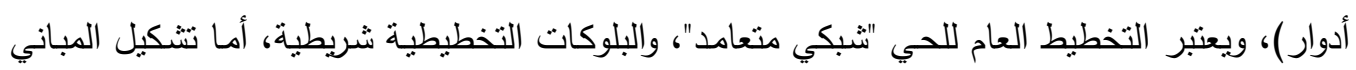
فإنها ذو نمط منفصل، ولا يوجد طابع بصري محدد للحي بل هو مختلط بين عدة اتجاهات، والثكل رقم (12) يوضح النمط العمراني لحي الورود. 5 2-5 حي الملك فيصل: 2-2 يقع حي الملك فيصل في شرق مدينة الرياض وتبلغ مساحته حوالي (418.00 هتكار ) ويحده من الثمال

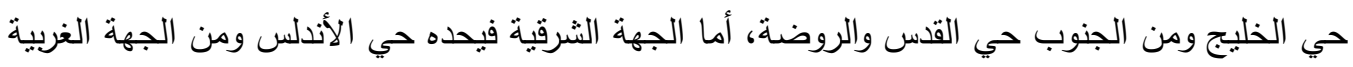
حي الحمراء، والثكل الهندسي للمسقط عبارة عن مستطيل يواجهه محوره الطولي اتجاه الثمال الغربي. ويتآلف حي الملك فيصل من ثلاثة مجاورات سكنية، والعامل المشترك بينها هو المجموعة السكنية 
النمطية التي تمثل نواة تخطيطية تتمركز بها الخدمات التعليمية، ويلاحظ زيادة المدارس أجمالا بالحي حيث يحتوى على (14مدرسة)، مما يشير إلى ضرورة إعادة النظر في هيكل توزيع الخدمات التعليمية (كماً ونوعاً وتوزيعاً). والثكل رقم (13) يوضح النمط العمراني لحي الملك فيصل.

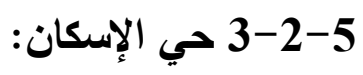

يقع حي الإسكان جنوب الرياض على مساحة حوالي (583.00 هيكتار ) ويحده من الثـمال امتداد الطريق الدائري ومن الجنوب طريق الخرج والمدينة الصناعية الجديدة وحي طيبه، حيث تبدو المجموعات التيات السكنية وحدة متلاحمة تتمركز فيها الخدمات، ويغلب على شبكة الطرق الاتجاه الحلقي ذات النهايات

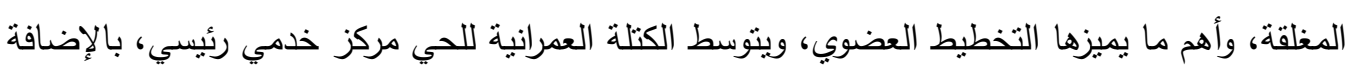
لمراكز فرعية منتشرة وغالبيتها خدمات تعليمية، حيث يحوى الحي على (26) مدرسة ابتدائية ومتوسطة، والثكل (14) يوضح النمط العمراني لحي الإسكان.

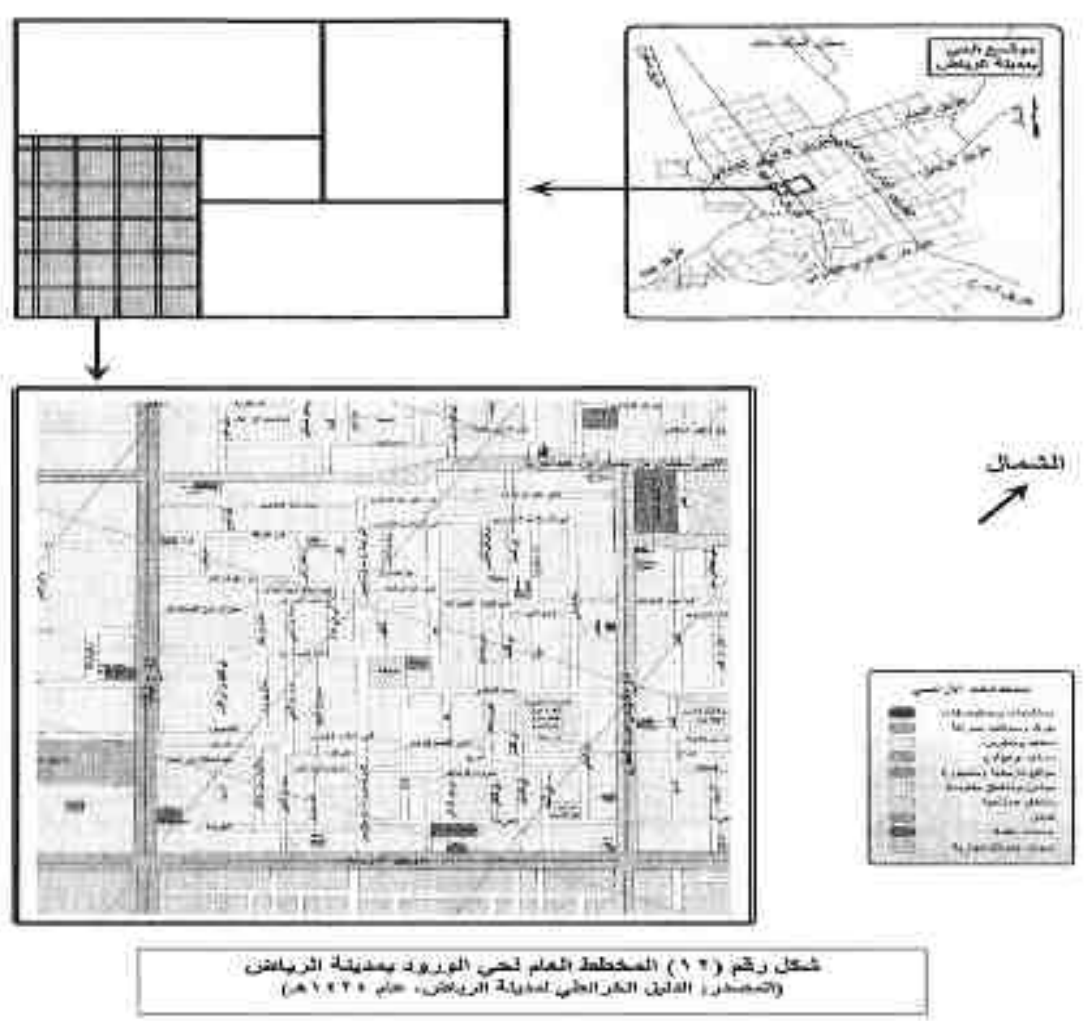




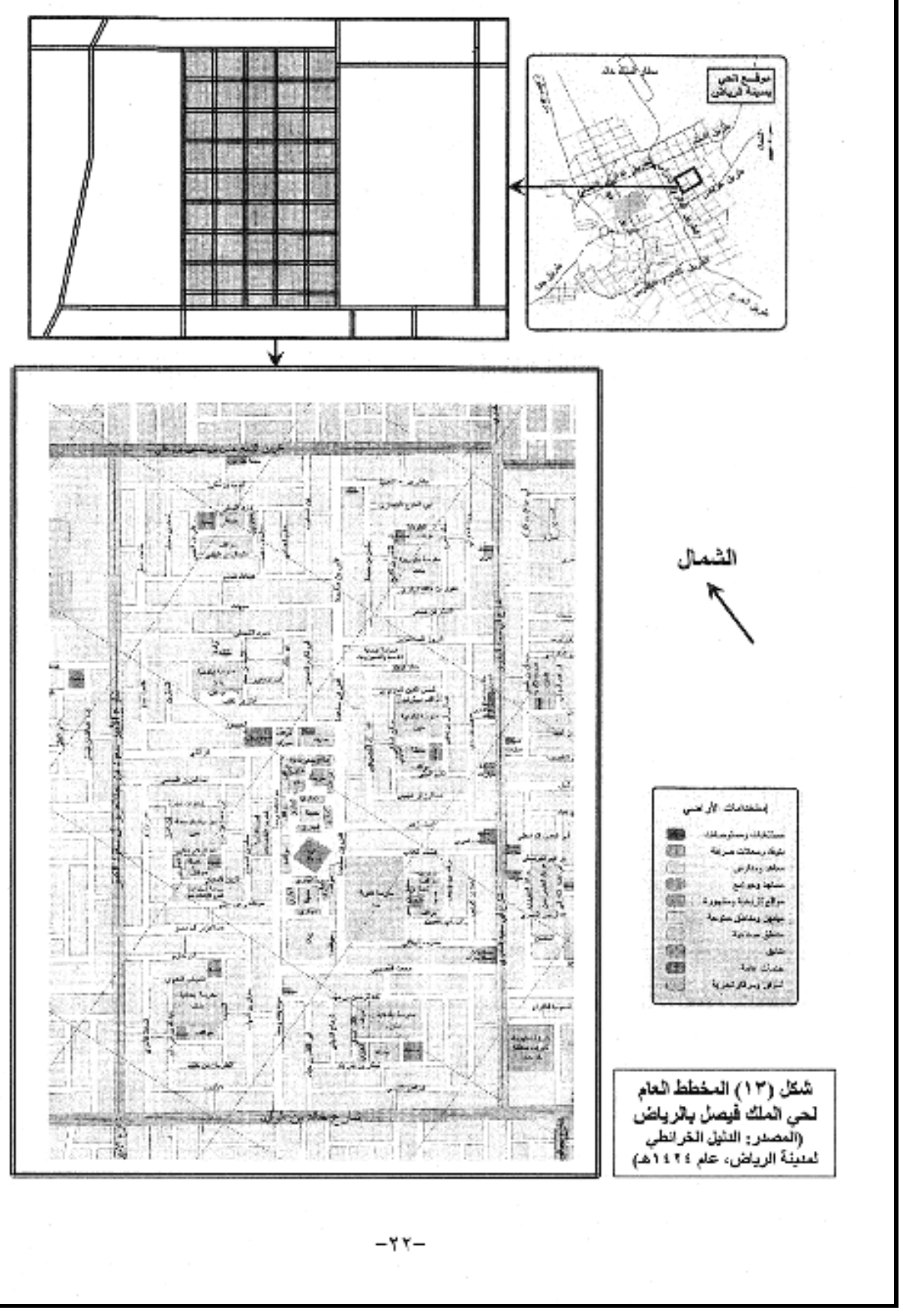



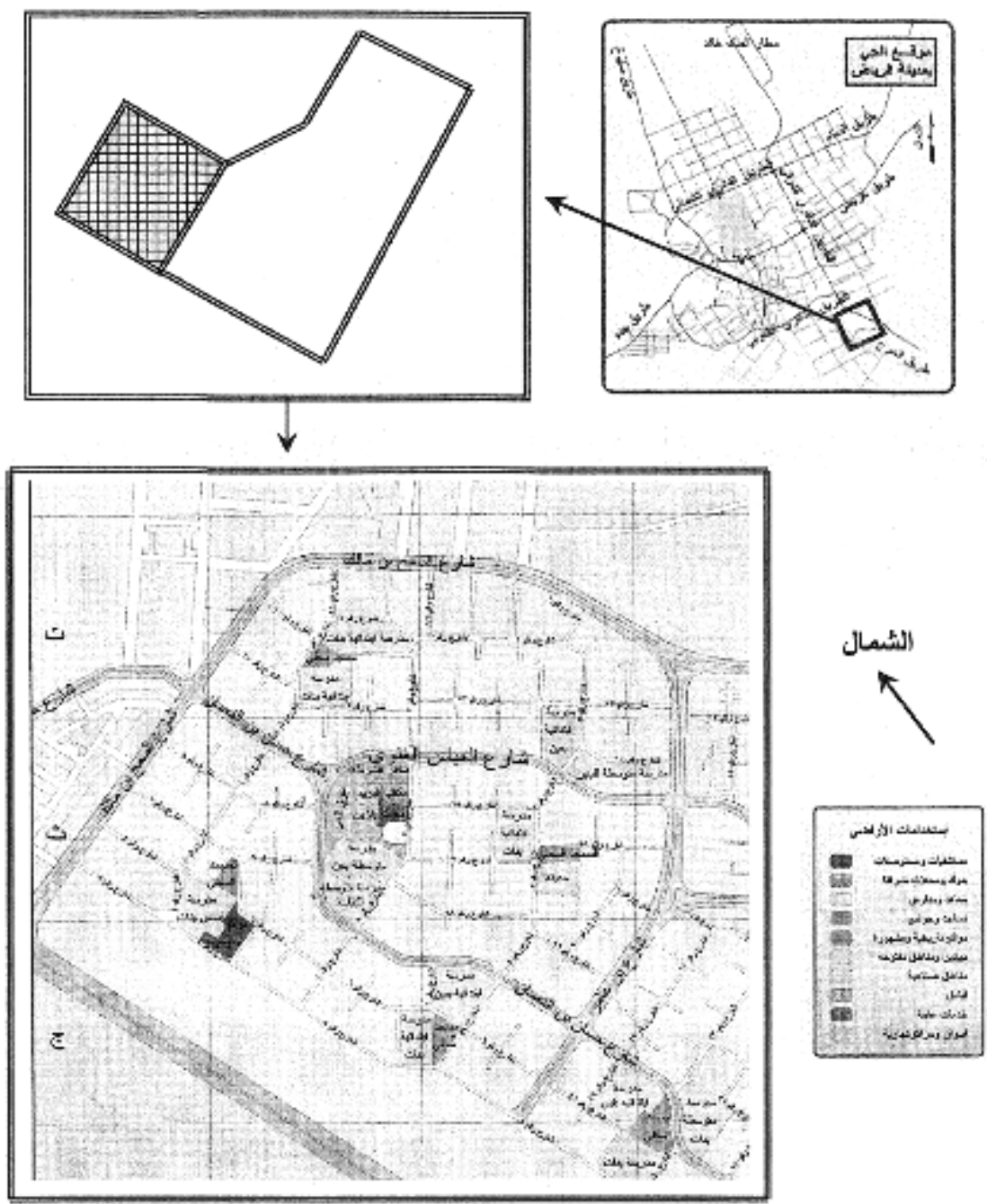

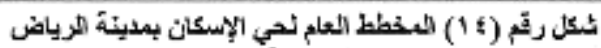

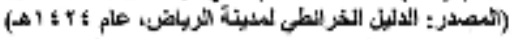

5-3 تقييم مدى التوافق البيئي للأنماط العمرانية للأحياء مجال الدارة. 
- تم استخلاص مجموعة من المعايير التخطيطية والبيئية، وشملت المعايير سبعة مجموعات أساسية تتضمن أنساق كل من الفراغات والحركة والخدمات، بالإضافة لأنماط الأنسجة العمرانية وتنشكيل الكتل

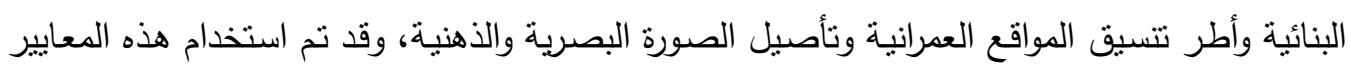
في قياس الأداء البيئي والعمراني لأحياء مجال البحث والدراسـة، والجدول رقم (2) يوضح نتائج تقيبيم التوافق البيئي والعمراني لهذه الأحياء.

جدول (2) مؤثرات التوافق البيئي والعمراني للأحياء المختارة في مدينة الرياض

\begin{tabular}{|c|c|c|c|c|}
\hline (الجنوب) الإسكان) & حي الملك فيصل & حي الورود (الثمار) & \multicolumn{2}{|c|}{ معايير التوافق البيئي للأنماط العمرانية بالأحياء السكنية } \\
\hline 00 & 000 & 000 & 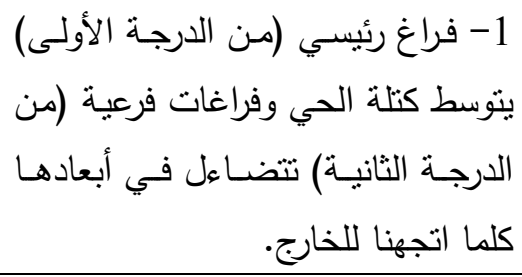 & أولاً: أنساق توزيع \\
\hline 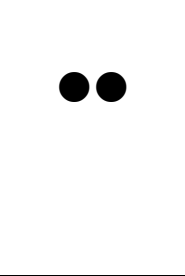 & D & 00 & 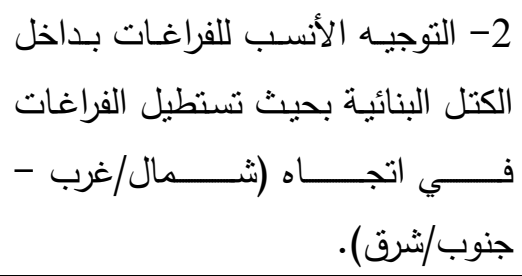 & $\begin{array}{l}\text { Open spaces } \\
\text { pattern }\end{array}$ \\
\hline & & 00 & 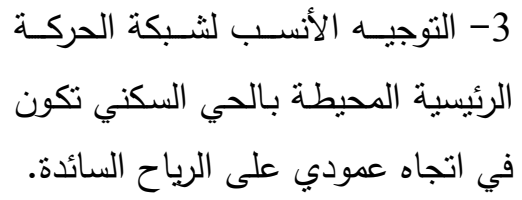 & الحركة العمرانية: أنساق \\
\hline & 00 & 00 & 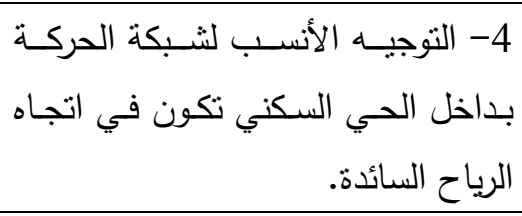 & $\begin{array}{l}\text { Movement } \\
\text { pattern }\end{array}$ \\
\hline 0 & 000 & 0 & 5- نتمركز الخدمات الرئيسية بـالحي & ثالثاً أنساق توزيع \\
\hline & 000 & 0 & 6- ترتبط مكانباً مـع المركز الرئيسي الفرعية في منظومــ & $\begin{array}{c}\text { Services } \\
\text { pattern }\end{array}$ \\
\hline
\end{tabular}




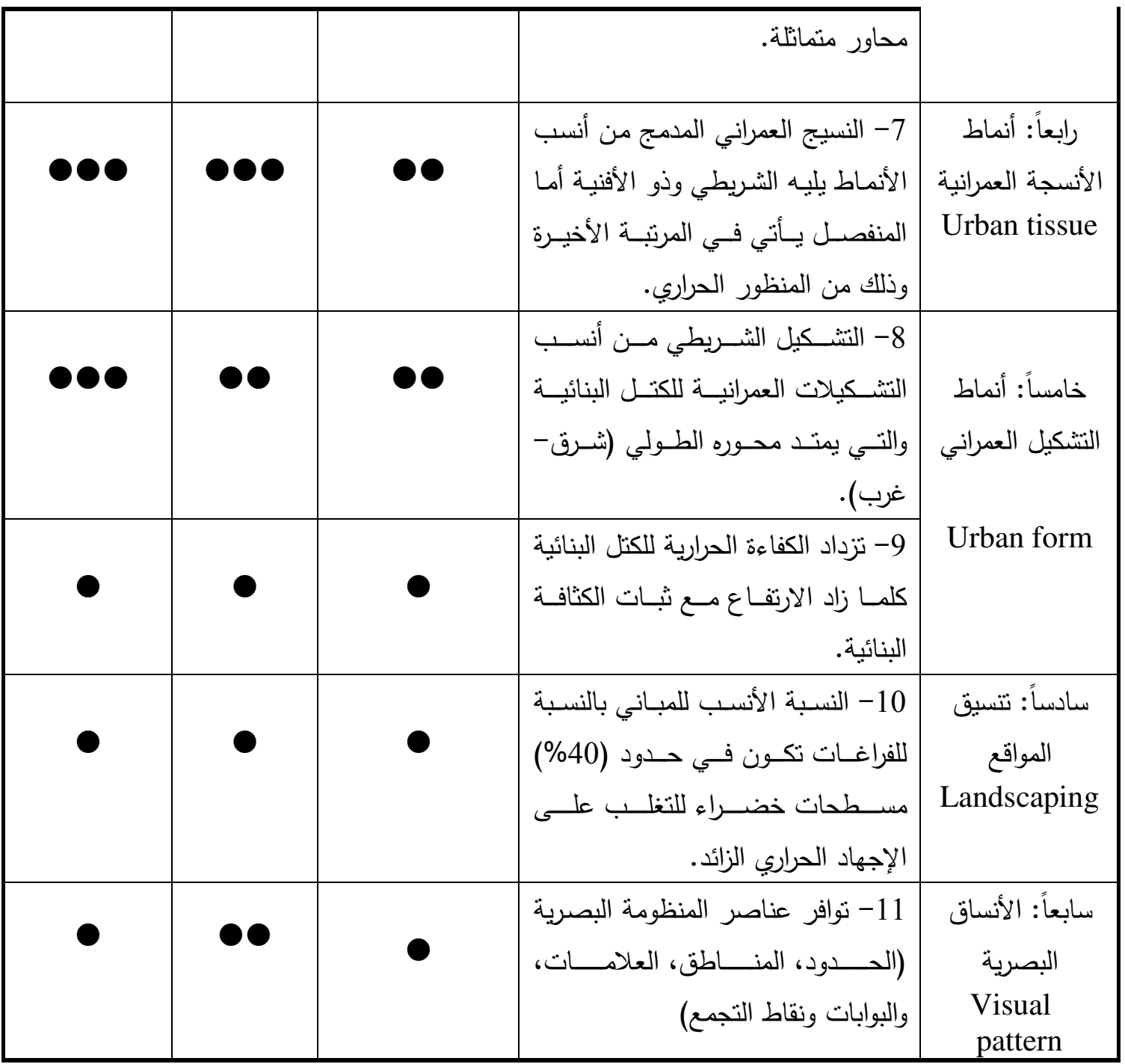

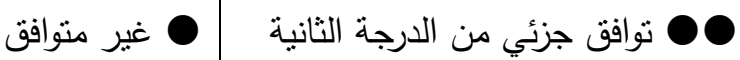

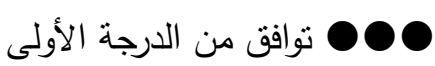
المصدر : إعداد الباحث 
- أوضحت نتائج الدراسـات التقيمية محدوديـة النوافق البيئي للأنماط العمرانيـة المستخدمة في لأحياء السكنية مجال البحث والدراسة، وتؤكدها المؤثرات الرقمية الموضحة بالجدول رقم (3).

\section{جدول (3) المؤثرات الرقمية لتوافق المعايير البيئية في تخطيط الأحياء السكنية}

\begin{tabular}{|c|c|c|c|}
\hline حي الإسكان & حي الملك فيصل & حي الورود & الأحياء السكنية \\
\hline$\% 45$ & $\% 36$ & $\% 9$ & نوافق من الدرجة الأولى \\
\hline$\% 27$ & $\% 45$ & $\% 45$ & نوافق جزئي من الدرجة الثانية \\
\hline$\% 28$ & $\% 19$ & $\% 46$ & غير منوافق \\
\hline
\end{tabular}

- حيث شملت نسبة المعايير المتوافقة حوالي (45\%) لحي الإسكان مقابل (36\%) لحي الملك فيصل، (9\%) لحي الورود، كذلك القصور في بعض المعايير اللازمة للأحياء السكنية منها الأبعاد الفراغية الفية

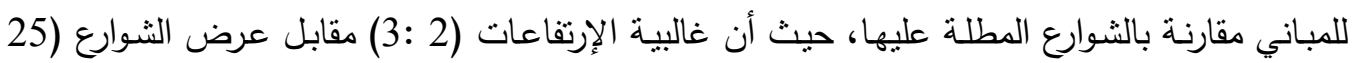

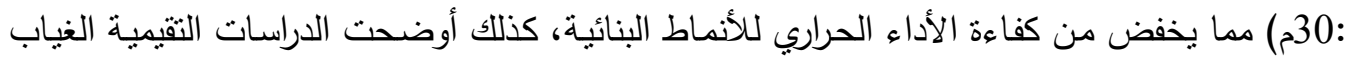
النسبي لعناصر تتسيق الموقع على مستوى الأحياء، وكذلك محدودية الفراغات العامة التي تحفف من الإجهاد الحراري الواقع على الكتلة العمرانية.

\section{6 - 6تائج وتوصيات البحث.}

- في إطار الدراسات النظرية والتطبيقية نوصل البحث إلى خطوط إرشادية للأنماط العمرانية المتوافقة

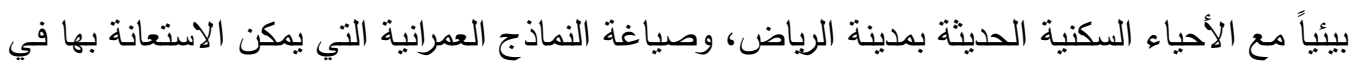
تخطيط الأحياء السكنية المستهدفة، طبقاً للمخطط الإستراتيجي للمدينة حتى عام (1442هـ). وقد أثتب البحث صحة الفرضية النظريـة المطروحة والتي تنتير إلى محدوديـة التوافق البيئي للأنمـاط العمرانيـة بالأحياء التي شملها البحث بالتحليل، ويؤكد ذلك ما يلي:

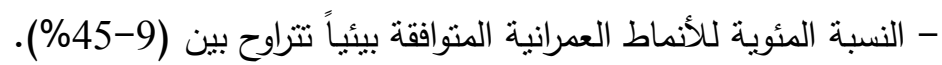

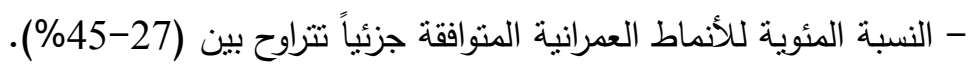

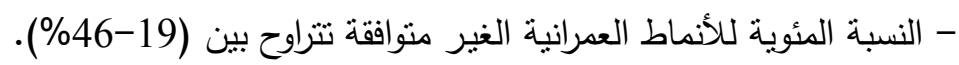

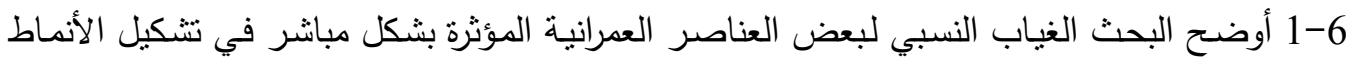

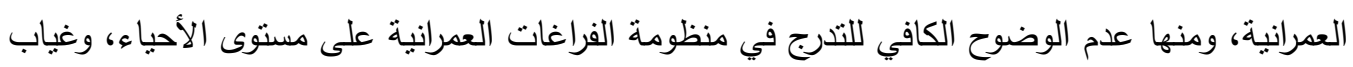


الصورة البصرية والذهنية الني نراعى الثخصية والهوية العمرانية للأحياء السكنية وتعكس الخلفية الثقافية والحضارية للمجتمعات العمرانية.

6-2 أكد البحث على مناسبة النمط التخطيطي الثريطي للأحياء السكنية بمدينة الرياض (من وجهة

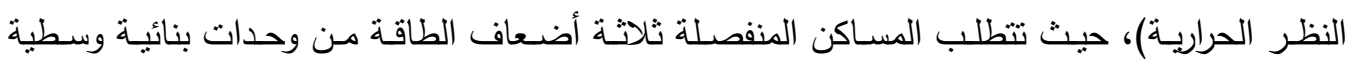
مماتلة، كذللك يتحسن الأداء الحراري للأنماط بزيادة الارتفاع مع ثبات كثنافتها البنائية، بمقدار (50\%)

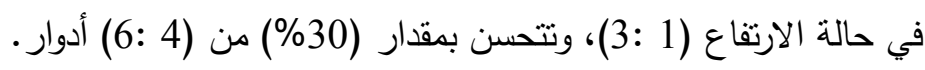

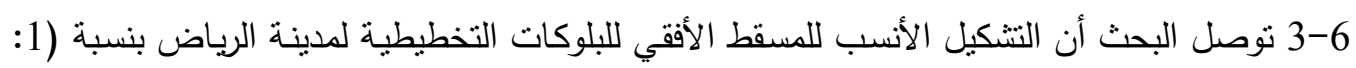
1.5)، (1: 2)، والتوجيه الأساسي لها يكون (شمال شرق -جنوب غرب)، ويميل محورها الطولي بزاوية التهبية

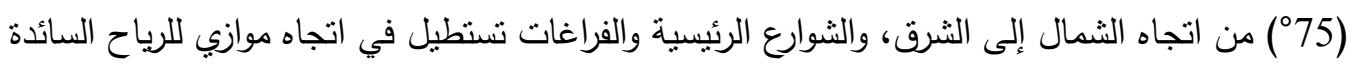
(شمال غرب-جنوب شرق) لتسمح بمرور الرياح. 6-4 أكد البحث تفوق ثأثثر التوجيه الجغرافي للمباني على نسبة الفتحات بالواجهات وخصائص مواد التهاد

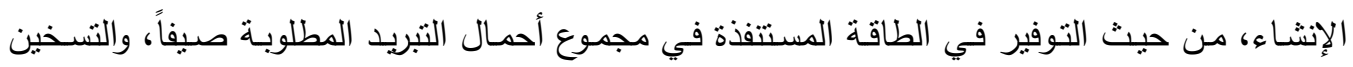

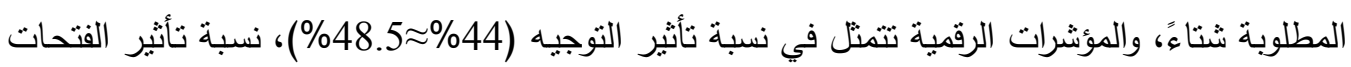

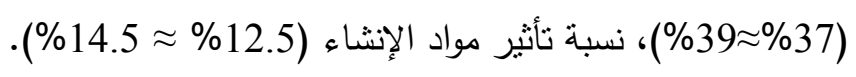

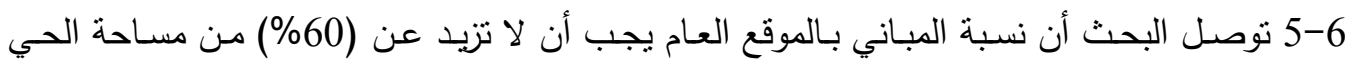

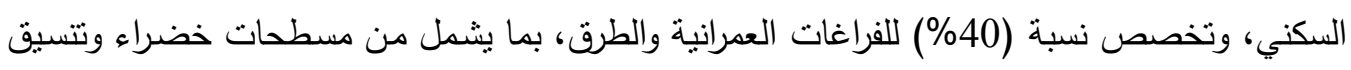

مواقع، وهذه المؤشرات طبقا لتوجهات التخطيط المستدام بالمدن الصحراوية. 6-6 يوصي البحث بإعادة النظر في الأحياء السكنية الحديثة والتي هي تحت التبطن التفيذ ومراجعة أنماطها العمرانية وبحث أطر رفع كفاءتها البيئية، ومراعاة مشاركة المعيار البيئي في الأحياء السكنية المستهدفة بالمخطط الاستراتيجي لمدينة الرياض، كذلك يوصي البحث بتفعيل دور البحوث التطبيقية والتجريبية في المجال العمراني طبقاً للظروف الحيوية والمكانية والاجتماعية. 6-7 يوصي البحث بالتوسع في إنثاء المراصد الحضرية" التي تعني بشئون العمران والبيئة، والتأكيد

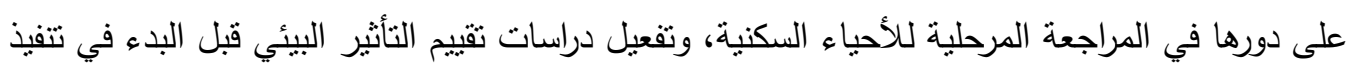
المشروعات وبرامج التتمية، بما يدعم تقويم مسار العمران بالمدن.

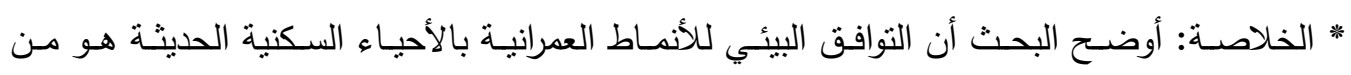

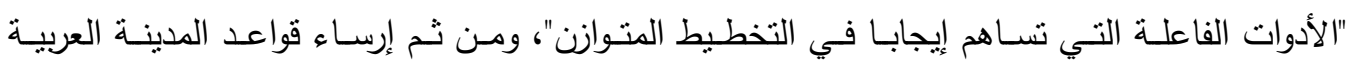
المستدامة، لكي تكون مدينة الرياض نموذجاً يحتذي في طليعة هذه المدن بإذن الله. 


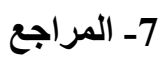

- الأمم المتحدة، تحسين كفاءة استخدام الطاقة في قطاع الأبنية، تحليل الخيارات في دول مختارة أعضاء في الإسكوا، نيويورك، (1422هـ، الموافق 2001م).

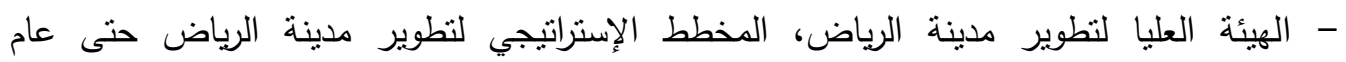

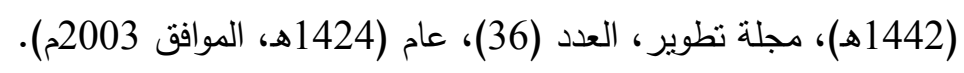

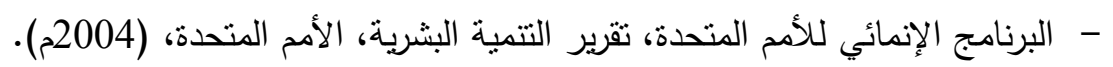
- أمانة الرياض، الدليل ألخرائطي والمعايير والمعدلات والاشتراطات التصميمية والتخطيطية لمدينة الرياض، إدارة المشروعات، المملكة السعودية، (1424ه، الموافق ولن 2003م). - أسامه خليل، الفكر البيئي المستدام في تخطبط المدن بالمناطق الصحراوية، بحث بالمجلة المبلة

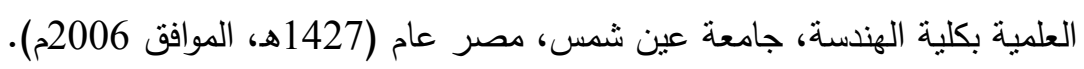

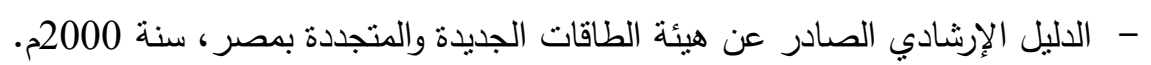

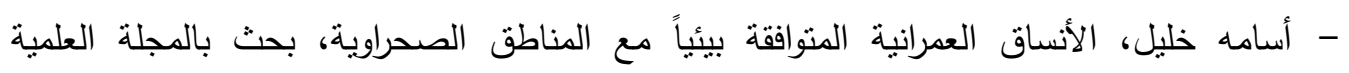
لكلية التخطيط الإقليمي والعمراني - جامعة القاهرة، مصر ، عام (2005م).

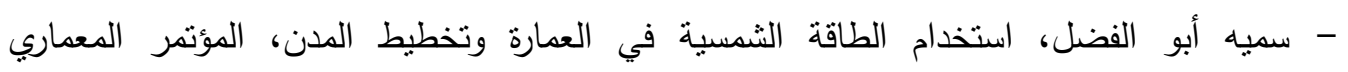
الدولي الخامس، العمران والبيئة .. الفكر والتطبيق، كلية الهندسية، مصر ، سنة 2003م.

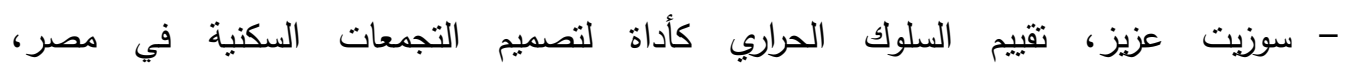
دكتوراه، جامعة القاهرة، سنة (1989م).

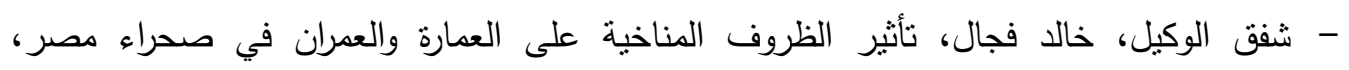
ندوة التتمية العمرانية في المناطق الصحراوية، المملكة السعودية، عام (2002م).

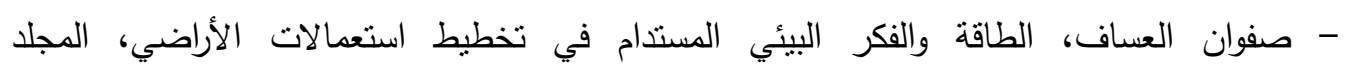

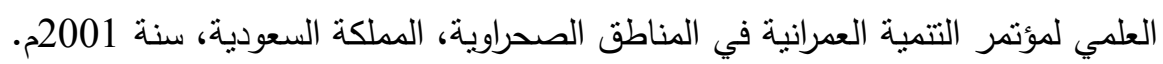
- عبد، القصيران، البعد البيئي في تخطط وتصميم المدينة، بحث منشور في فئنية ندوة الإبداع

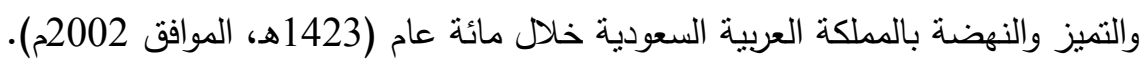
- مصلحة الأرصاد الجوية وحماية البيئة، الكتاب الإحصائي السنوي بالمملكة العربية السعودية،

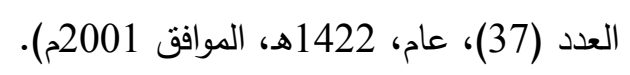

- - على باهمام ، تأثثير النمو الإنكاني في بيئة المدن في المناطق الصحراوية، المؤتمر المعماري

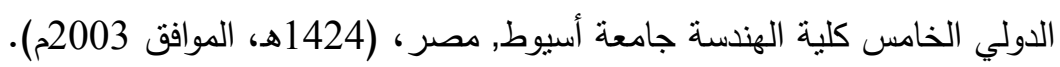

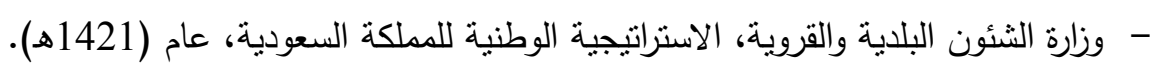

- Gupta, A,: building clusters and solar exposures, Indian Institute of Technology, Delhi, (1986). 
- V. Olgay, "Design With Climate, Bioclimatic Approach To Architectural Regionalism", Princeton University Press, N.J., (1976).

- Peter \& Philip, Energy and Urban built form, Butterworth's, London, (1987). 